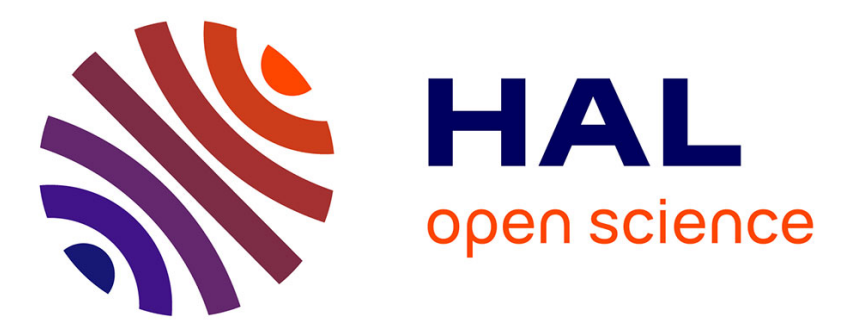

\title{
De generatio regum aragonum : une variante médiévale inédite de l'histoire des rois d'Aragon (et une source non identifiée de Lucio Marineo Sículo)
}

Georges Martin, Jean-Pierre Jardin

\section{- To cite this version:}

Georges Martin, Jean-Pierre Jardin. De generatio regum aragonum: une variante médiévale inédite de l'histoire des rois d'Aragon (et une source non identifiée de Lucio Marineo Sículo). Cahiers de linguistique hispanique médiévale, 1999, N²2, pp.177-225. halshs-00112095

\section{HAL Id: halshs-00112095 \\ https://shs.hal.science/halshs-00112095}

Submitted on 7 Nov 2006

HAL is a multi-disciplinary open access archive for the deposit and dissemination of scientific research documents, whether they are published or not. The documents may come from teaching and research institutions in France or abroad, or from public or private research centers.
L'archive ouverte pluridisciplinaire HAL, est destinée au dépôt et à la diffusion de documents scientifiques de niveau recherche, publiés ou non, émanant des établissements d'enseignement et de recherche français ou étrangers, des laboratoires publics ou privés. 


\title{
GENERATIO REGUM ARAGONUM. \\ Une variante médiévale inédite de l'histoire des rois d'Aragon \\ (et une source non identifiée de Lucio Marineo Sículo)*
}

\author{
Jean-Pierre JARDIN \\ (Université de la Sorbonne-Nouvelle, Paris III) \\ Georges MARTIN \\ (Université Paris-Sorbonne, Paris IV)
}

Dans son Historia de la historiografía española, Benito Sánchez Alonso ${ }^{1}$ signalait l'existence d'un «Chronicon aragonais du XIIe siècle» qu'il n'avait pas eu loisir d'examiner. Il en donnait le titre d'après le Diccionario de Muñoz y Romero², Chronicon regum Aragoniae ab Hispaniae clade et Roderico rege usque ad obitum Ranimiri monachi Aragonum regis. Anno MCXXXVII, et indiquait, suivant encore Muñoz, le lieu de conservation du manuscrit et sa cote : Escurial, C-II-7. Analysant quant à lui le contenu du volume, le Père Guillermo Antolín ${ }^{3}$ notait dans son catalogue : «XIX. (fol. 147). [Descendientes de Iñigo Arista]». Depuis ces mentions laconiques et contradictoires, nul, à notre connaissance, ne s'est intéressé à ce texte. Il demeure, à ce jour, inconnu des spécialistes de l'historiographie espagnole médiévale.

Les folios $147 \mathrm{r}^{\circ}-148 \mathrm{r}^{\circ}$ du manuscrit C-II-7 de la Real Biblioteca de El Escorial contiennent, en effet, deux courtes pièces historiographiques. La première (fol. $147 \mathrm{r}^{\circ}$ ) est une généalogie dynastique qui déroule, conformément au modèle fondé par la Chronique de Saint-Jean de la Peña, les successions de ce qui était regardé comme la seconde dynastie royale navarro-aragonaise depuis Iñigo Arista jusqu'à un roi «Joannes» qu'on tiendrait, à première vue, pour être Jean Ier. Un De genealogia regum Aragonum, en somme, présenté sous forme de tableau, les rois étant distribués en colonnes selon les territoires où ils régnèrent. La seconde pièce (fol. $147 \mathrm{v}^{\circ}-148 \mathrm{r}^{\circ}$ ) constitue un très sobre sommaire de l'histoire des premiers rois de Navarre et d'Aragon depuis la chute du royaume wisigothique d'Espagne jusqu'à la mort de Ramire II le Moine et s'apparente plutôt à ce que l'on désignait sous le titre de De primis regibus Aragonum. Toutes les deux sont écrites en latin. Elles furent composées à une date bien postérieure à celle que leur assignaient Muñoz et Sanchez Alonso. Bien que les relations génétiques de la

\footnotetext{
1* Publication papier : «Generatio regum Aragonum : une variante médiévale inédite de l'histoire des rois d'Aragon (et une source non identifiée de Lucio Marineo Sículo) », in : De la variation linguistique et textuelle. En l'honneur de Jean Roudil, 2 t., 2, Cahiers de linguistique hispanique médiévale, 22, 19981999, p. 177-225.

Benito SANCHEZ ALONSO, Historia de la historiografía española, Madrid : C.S.I.C., 1947, 1, p. 137 (2de éd. rev. et aug.; 1ère éd., 1941).

${ }^{2}$ Tomás MUÑOZ y ROMERO, Diccionario bibliográfico-histórico de los antiguos reinos, provincias, ciudades, villas, iglesias y santuarios de España, Madrid : Rivadeneyra, 1858, 1 (Aragón), p. 21.

${ }^{3}$ P. Guillermo ANTOLíN, Catálogo de los códices latinos de la Real Biblioteca del Escorial, Madrid: Imprenta helénica, 1910, 1, p. 234.
} 
généalogie et du sommaire soient loin d'être claires, ils forment à plus d'un titre un ensemble solidaire et cohérent. Conciliant les genres, nous avons décidé de les intituler tout uniment Generatio regum Aragonum. 


\section{TRANSCRIPTION}

\section{Critères}

Notre édition s'adresse aux historiens de l'historiographie et, de ce fait, se veut d'abord lisible. Nous avons donc choisi de ne pas reproduire la diversité des graphèmes (deux formes du «c», deux formes du «t», deux formes du «r», trois formes du «s», etc.). La dualité graphique $\mathrm{du} \ll \mathrm{i} »[\mathrm{i} / \mathrm{j}]$ et $\mathrm{du} \ll \mathrm{u} »[\mathrm{u} / \mathrm{v}]$ a été réduite à l'usage contemporain. Nous avons transcrit en majuscule l'initiale des noms propres.

Dans le manuscrit, la ponctuation se limite à détacher les dates entre deux points et, quelquefois, à marquer d'un point la fin d'un paragraphe. Là encore, nous avons tiré le texte vers nos propres conventions quant à la ponctuation phrastique (majuscule initiale, point final) et à la présentation des dates (parenthèses ou absence de ponctuation). En une occasion, le signe [./.] a été transcrit par ce qui nous est apparu comme son équivalent contemporain : [:].

Les brefs commentaires portés en marge du sommaire historique ont été intégrés au texte entre crochets doubles à hauteur du propos auquel ils s'appliquent. A cela près, et dans les limites des impératifs éditoriaux (emploi de deux casses pour transcrire la généalogie dynastique), nous avons grossièrement respecté la disposition du texte manuscrit sur le folio : alinéas, sauts de ligne et, pour la généalogie dynastique, colonnes. Nous n'avons pas indiqué la coupure des lignes.

La résolution des abréviations, en revanche, est toujours signalée par des caractères italiques. L'écriture du manuscrit étant généralement peu soignée, nous avons marqué nos doutes en transcrivant entre crochets simples la forme peu lisible ou grammaticalement suspecte. Les lexies soudées ont été séparées.

La brièveté du texte nous a permis de répondre à l'attente des paléographes et des linguistes par une reproduction photographique d'ensemble.

Texte

$\left(\right.$ fol. $\left.147 r^{\circ}\right)$

Ennecus Arista de comitatu Bigorre (840).

Guarcias Enyegues filius

Sancius Guarces ii filius

Guarcias Sanctionis filius

Sanctius maiore filius

[[filii]]

Ranimirus in Aragonia

Guarcias in Navarra

Ferdinandus in Castella

Gondissalvus in

rex ex prima uxore

rex ex $2^{\mathrm{a}}$ uxore

rex ex $2^{\mathrm{a}}$ uxore

Suprarbiis rex ex

$2^{\mathrm{a}}$ uxore 
Sanctius Remires qui occidit Guarciam et fuit rex Navarre erectus per Navarrenses

[[filii]]

Petrus successit in Aragonia et Navarra

\section{Garcias filius}

Aldefonsus
successit
in Aragonia
et Navarra

Sancius filius qui occidit

Ranimirum patruum suum mortuus sine prole vassalli dederunt se Ranimiro patruo

\author{
Ranimirus \\ Patronilla \\ uxor Raymundi \\ Berengarii \\ comitis \\ Barchinone
}

Aldefonsus filius

primus rex

Aragonum post

unionem es[se]

Petrus filius

Jacobus filius

Petrus filius habuit uxorem Constanciam filiam Manfredi regis Sicilie utriusque

Alfonsus filius

Jacobus frater

Alfonsus filius Jacobi

Petrus filius

Joannes

Dux ego de matre rex conjuge marchio patre

[Marte fame] pressi [Nav]arros dum [--prem] degi

et sine jactura tenui domino sua jura.

$\left(\right.$ fol. $\left.147 v^{\circ}\right)$

Rodericus rex Ispanie dedit causam prodicioni comitis Juliani comitis Cantabrie cuius prodicione Ismaelite seu Sarraceni intrarunt per regnum Granate Ispaniam et conquissiverunt eam usque ad Piraneos montes et fuit anno Domini 667 xi die novembris demptis montibus Asturiarum et aliqua parte montium Pirineii et stetit occupata usque ad annum 1002.

[[Prima electio regis Aragonum de Garcia Eximenez qui conquisivit Navarram]]

Et christiani qui superfuerunt in montibus Uruel seu Sanct Joanne de la Penya in provincia Aragonie elegerunt in eorum regem Garciam Eximenez ex genere Gotorum anno Domini dccviii et christiani erant numero dc et iste abstulit vi armorum Ismalitis maximam partem Navarre et obiit anno 758.

Garcias Enyego filius conquisiuit civitatem Pampilone et intitulabatur rex Navarre. Obiit 802. 
Fortunyo filius accepit uxorem filiam Gualindo [comitissam] Aragonie qui fuit filius Aznar primi comitis Aragonie. Pro respectu uxoris sue fuit comes Aragonum. Obiit 815.

Sanctius Garcia filius fuit rex Navarre Suprarbii et Ripacurcie et comes Aragonie. Obiit in bello per Almancor de Cardona anno Domini 835 et regna remanserunt sine domino et sine herede.

Ennecus Arista anno decc xxxx descendit a comitatu Bigorre et morabatur in montibus Pirineis et bella vincendo ex Ismaelitas eisque [a-] fere [-] terram passim per [dictos] descendit ad planas Navarre. Et Navarrenses atque Aragonenses apud Jucar se in eorum principem eligerunt sub conditione quod daret eis foros et judicem qui vocaretur Justicia Aragonum et privilegium unionis et obiit 864.

Garcias Enyegues filius successit in Navarra Aragonia et Castella. Obiit 881.

Sanctius Guarces ii Auarca fuit in regem juratus et obiit 936.

Guarcias Sanctionis filius successit in regno. Obiit 964.

Sanctius Maiore filius dominatus est Navarram Aragoniam Castellam Portugaliam et ducatum Cantabrie et Vasconia subdit se sibi et dominatus est regnum Suprarbii et Ripacurcie. Ex prima muliere habuit filium Ranimirum et ex $2^{\mathrm{a}}$ habuit tres filios : Garciam Ferdinandum Gondissalvum.

[Hic fuit imperator Ispanie et per uxorem rex Castelle]

Et successit in Navarra Guarcias et in Castella Ferdinandus et Gondissalvus in Suprarbiis

\section{$\left(\right.$ fol. $\left.148 r^{\circ}\right)$}

[[Primus qui se intitulavit rex Aragonum]]

et Ranimirus in Aragonia et fuit primus qui vocatus fuit rex Aragonum. Filius Sanctii maioris ex prima uxore. Obiit 1063.

[[2us rex]]

Sanctius Remirez filius Ranimiri. Et iste devincit et occidit in bello Guarciam eius patruum regem Navarre et ex tunc Navarrenses jurarunt eum in regem anno 1094 et obiit ipso eodem anno.

Petrus filius successit in regnis predictis. Obiit 1109.

Aldefonsus frater Petri successit in regnis Aragonie et Navarre per se et fuit rex Castelle per uxorem.

Ranimirus frater predictorum et tercius filius Sanctii Remirez monacus extractus a monasterio fuit rex Aragonum et in Navarra super totum populum . Et cum concordia seu arbitrio personarum electarum utriusque regni decursit ut Garcias Remirez [----] rex 
super milites et infancones. Et habuit Patronillam que mixta fuit cum Raymundo Berengarii comite Barchinone. Et obiit Ranimirus 1139.

\section{COMMENTAIRE}

\section{Manuscrit.}

Le volume qui conserve le Generatio fut la propriété d'Antonio Agustín, archevêque de Tarragone. A la mort de celui-ci, en 1586, Philippe II en décida l'acquisition par la bibliothèque du monastère de l'Escurial ${ }^{4}$. Il offre un contenu varié, bien analysé par le Père Antolín, où dominent les constitutions synodales et capitulaires barcelonaises et de Tarragone ainsi que divers privilèges accordés à la ville de Barcelone par les rois d'Aragon. La datation de ces documents ne va jamais au delà de la première moitié du XIVe siècle. C'est aussi du XIVe siècle que le Père Antolín datait le manuscrit dans son ensembles. En vérité, le volume est factice. Les chartes ecclésiastiques (fol. 1-44) constituent une première unité : même papier, même écriture, la numérotation se fait en chiffres romains. Un ensemble de chartes royales concédées par Jacques Ier, Pierre Ier, Alphonse II, Jacques II, Alphonse III et Pierre IV (fol. 45-123) forme une seconde unité : l'écriture change, la numérotation des folios en chiffres romains recommence à I, elle est redoublée par une numérotation en chiffres arabes qui s'efforce d'associer les deux unités physiques en continuant la numération des folios antérieurs. Une troisième unité regroupe les folios 124 à 139 : le papier (marqué d'un filigrane à fleur de lys datant, au plus tard, du début du XVe siècle) change, deux nouvelles écritures apparaissent, il y a rupture chronologique du contenu diplomatique qui revient au règne de Jacques II puis à celui de Jacques Ier. Jusqu'ici, les écritures pourraient toutes dater du XIVe siècle. A partir du folio 140 apparaissent des écritures plus tardives, les textes sont généralement catalans et non plus latins, l'un d'eux (fol. 142) est daté de novembre 1425. Les folios 147-148, contenant le Generatio, appartiennent à un même cahier qui forme les folios 145 à 148; le papier est filigrané d'un char à deux roues produit en Italie à partir du dernier tiers du XVe siècle $^{6}$. L'écriture est de la fin du XVe ou du début du XVIe.

\section{Rédaction.}

Généalogie dynastique et sommaire historique sont très étroitement apparentés. L'orthographe nominale est identique dans les deux textes, alors qu'elle varie considérablement dans l'historiographie de l'Espagne orientale. De même que le

\footnotetext{
${ }^{4}$ Ibid., p. xlii-xliii.

${ }^{5}$ Ibid., p. 218.

${ }^{6}$ C. M. BRIQUET, Les filigranes. Dictionnaire historique des marques du papier dès leur apparition vers 1282 jusqu'en 1600 [fac-similé par Allan Stevenson, Amsterdam : The Paper Publications Society, 1968, 1, p. 228 (figure 3540), reproduction dans le t. 3]. Pistoie, 1470; Florence, 1463-1478; Palerme, 1471; Venise, 1490; Fabriano, 1470.
} 
sommaire historique, où le procédé est plus utile, l'homme ayant le même nom que l'arrière-petit-fils de Garsias Jimenez, fondateur de la première lignée royale, la généalogie, qui ne développe pourtant que la seconde dynastie, identifie numériquement le petit-fils d'Iñigo Arista : «Sancius Guarces $i i »$. Quant au contenu historique, nulle contradiction entre les deux textes. Mieux : le statut attribué à Ramire Ier d'Aragon de fils aîné légitime de Sanche le Grand et l'imputation de la mort de Garsias Sanchez II de Navarre à son neveu Sanche Ramirez forment un couple d'informations qui, en tant que tel, écarte communément nos textes de toute la tradition historiographique médiévale espagnole. Nous verrons qu'il faut attendre 1509 pour trouver, dans le De genealogia regum Aragonum ${ }^{7}$, de Lucio Marineo Sículo, cette double indication, au demeurant moins assurée quant à la filiation légitime de Ramires.

Unité de rédaction, alors? Que la généalogie et le sommaire se distinguent par les termes de leur recensement tient à la différence des genres et des intentions; cela ne saurait infirmer la thèse d'une unité rédactionnelle. La disposition scripturale des deux textes doit-elle, en revanche, être interprétée comme un signe de discrimination? Une énigme qui semble une déclaration d'autorité sépare les deux composantes du Generatio et paraît n'assumer que la généalogie; le bas du folio reste en blanc, le sommaire étant repoussé au verso. Mais nous verrons que le positionnement de l'énigme ressortit peutêtre à une habileté de l'auteur et n'est pas nécessairement une trace génétique. La généalogie contient des informations que n'offre pas, sur le segment historique correspondant, le sommaire. Elle indique, par exemple, que Gonzague de Sobrarbe, fils de Sanche le Grand, mourut sans postérité et que ses vassaux se «donnèrent» alors à Ramire Ier d'Aragon. Elle ajoute aussi que ce dernier fut tué par Sanche II de Castille. Mais on observe cependant que, dans les deux cas, la logique du sommaire semble être de retenir ce que firent les rois -et ainsi est-il déclaré que Sanche Ramirez vainquit et tua son oncle Garsias de Navarre- plutôt que ce qui leur fut fait. Nous verrons également que rien dans les rapports qu'entretiennent les deux composantes du Generatio avec la tradition historiographique ne permet de les dissocier dans la chronologie et que les oeuvres qui porteront la trace de l'influence de nos textes se seront inspirées d'un Generatio constitué en unité textuelle.

Outre la généalogie et le sommaire, le manuscrit conserve des commentaires portés en marge du second. Ces notes sont d'un historien avisé. Elles ont inspiré suffisamment de respect au copiste pour qu'il ait déporté très à droite sur le folio le texte

\footnotetext{
7 Lucio MARINEO SíCULO, De genealogia regum Aragonum, Saragosse : Georgius Cocus Alemanus, 1509. L'oeuvre se voit aussi attribuer les titres de De Aragoniae regibus et eorum rebus gestis et -inexactement, puisque le récit se prolonge jusqu'au roi contemporain de la rédaction- de De primis Aragoniae regibus. Désormais : De genealogia. Traduction au castillan par Juan de Molina, Cronica d'Aragon, Valence : Al molí de la Rouella, 1524; fac-similé : Lucio MARINEO SíCULO, Cronica d'Aragon, Barcelone : El Albir (Biblioteca de historia hispánica; Crónicas, 1), 1974 (à l'occasion, Cronica d'Aragon).

${ }^{8}$ Vid. infra passages correspondant aux notes 55,59 et 60 .
} 
du sommaire afin de les mettre en valeur. Il ne s'agit point d'appels ou de titres inscrits par l'auteur du sommaire : ces annotations complémentent et semblent même, à l'occasion, démentir le propos du texte principal. Pourquoi l'auteur du sommaire auraitil porté en marge du paragraphe qu'il consacre à Sanche le Grand l'indication «Hic fuit imperator Ispanie et per uxorem rex Castelle», alors que celle-ci pouvait parfaitement figurer au coeur de son discours? Du reste, ne mentionne-t-il pas lui-même la Castille parmi les territoires sur lesquels s'exerçait déjà l'autorité de Garsias Iñíguez II, voire d'Iñigo Arista : «Garsias Enyegues filius successit in Navarra Aragonia et Castilla»? Mais plus encore : est-ce bien la même chose d'écrire que Garsias Jimenez fut élu «in provincia Aragonie» par les «christiani» réfugiés à Saint-Jean de la Peña et proclamer, comme le fait la note correspondante, que cet acte constitua la première « electio regis Aragonum »? Nullement, nous le verrons, si l'on rapporte ces propos aux évolutions sémantiques de l'historiographie médiévale de l'ouest de la Péninsule. Pas davantage, semble-t-il, si l'on s'en tient au texte du sommaire et à ses rapports avec le système des notes maginales. L'auteur du sommaire, en effet, réserve la première titulature territoriale au fils de Garsias Jimenez, Garsias Iñíguez, qui, après avoir conquis Pampelune, devient «rex Navarre». Dans le paragraphe consacré au fils de Garsias Iñiguez, Fortuné Garsès, il signale l'existence d'un «comes Aragonie», Aznar, puis, après le mariage de Fortuné avec la fille du comte Galindo, attribue au royal époux et, plus explicitement encore, à son fils Sanche Garsès la double titulature de «rex Navarre» et de «comes Aragonie». Aussi bien, parvenu à hauteur de Ramire, fils de Sanche le Grand, l'auteur du sommaire peut-il très logiquement déclarer : «fuit primus qui vocatus fuit rex Aragonum». En marge de ce propos, le commentateur, à son tour logique avec lui-même, nuance : «Primus qui se intitulavit rex Aragonum»-entendons : qui adopta formellement cette titulature.

Mais si ces marginalia ne sont pas consubstantiels au sommaire, sont-ils simplement le fait d'un copiste averti ou sont-ils l'oeuvre de l'auteur de la généalogie? Dans le second cas, il faudrait distinguer l'auteur du sommaire de celui de la généalogie et ordonner leur activité dans le temps. Le second, à l'heure de composer le Generatio, aurait annexé à son propre texte, et annoté, l'oeuvre du premier, dont il se serait du reste inspiré (mort de Garsias de Navarre dans un affrontement avec Sanche Ramirez). Les évolutions de la tradition historiographique -notamment sous le rapport de la titulature des premiers rois- pourraient aller dans le sens de cette seconde hypothèse. Si elle était fondée, l'existence des notes marginales ainsi que des données complémentaires apparaissant dans la généalogie (dédition du Sobrarbe à Ramire Ier, mort de celui-ci aux mains de Sanche Ramirez) seraient autant d'indices de ce que le sommaire historique aurait été intégré en l'état, sans que l'auteur de la généalogie l'ait modifié ni même interpolé. Ce point ne serait pas sans intérêt pour la suite de notre étude. Mais nous 
avons vu d'autres traits internes plaider en faveur de l'unité rédactionnelle des deux composantes du Generatio et nous verrons que les traces d'influence de l'oeuvre semblent indiquer qu'à leur tour les notes accompagnaient déjà le texte lorsque celui-ci fut reçu par les historiens.

Les questions soulevées par la genèse rédactionnelle du Generatio obligent donc à la prudence. C'est pourquoi, au moment d'étudier le sens de l'oeuvre et conjointement -démarche obligée dans l'univers de l'historiographie médiévale- d'établir ses rapports avec la tradition', nous avons distingué sommaire, notes marginales et généalogie.

\section{Tradition, signification}

Sommaire historique. Commençons par ce qui pourrait former le noyau primordial du Generatio. De l'entrée des Sarrasins en Espagne sous le règne de Rodéric à la mort de Ramire le Moine et au mariage de sa fille Pétronille avec Raymond Bérenger IV de Barcelone, il s'ajuste globalement au modèle créé dans les années 13691372 par la Chronique de Sain-Jean de la Peña ${ }^{10}$ et reconduit par la tradition qu'elle

\footnotetext{
${ }^{9}$ Cette tradition, hélas, nous est fort inégalement connue. La profuse production navarraise, aragonaise et catalane de la fin du XIV ${ }^{\mathrm{e}}$ siècle et du XVe reste souvent inédite ou difficile d'accès; des oeuvres ont été perdues, d'autres sont incomplètement conservées, beaucoup n'ont pas été étudiées. Nulle trace des «anciennes chroniques de Valdisar», dont Manuel Abellá considérait que notre texte était le résumé. Selon Ubieto la «chronique de San Victorián» dont se réclame souvent Vagad aurait aussi disparu. Disparue également, la seconde partie de la Grande chronique d'Espagne de l'Aragonais Jean Fernandez de Heredia (fin du XIVe siècle), qui devait comporter les origines de la royauté navarro-aragonaise. Parmi les Sommaires qui fleurirent dans la première moitié du XV siècle, une (brève) Genealogia regum Navarrae (Escurial, ms. N.I.13), une Genealogia comitum Barcinonae necnon et Aragoniae regum (Escurial, ms. M.J.29) et des Mémoires historiales de Catalogne composées en 1418 (B.N. de Madrid, ms. 2639) sont inédites, et nous n'avons pas pu consulter la traduction qu'aurait faite ABAD Y LASIERRA des Canoniques de tous les rois d'Aragon (1437). Le Livre des noblesses des rois, composé par Francesch (ou Jean Français) au milieu du $\mathrm{XV}^{\mathrm{e}}$ siècle est, à notre connaissance, inédit, comme le reste un Sommaire du peuplement de l'Espagne et des conquêtes de la Catalogne du dernier tiers du XVe siècle qui semble un résumé des Histoires de Tomich (SANCHEZ ALONSO, Historia..., p. 333). Inédite également une compilation généalogique navarraise de la même époque conservée à l'Escurial (ms. N.I.13). Le temps imparti pour mener notre étude nous a encore interdit de consulter une Généalogie des rois d'Aragon et de Navarre et des comtes de Barcelone dont l'édition est répertoriée par SANCHEZ ALONSO (Fuentes de la historia española e hispanoamericana, Madrid, 1927, 2de éd., article 1722), la Chronique de Garci Lopez de Roncevaux (1405), le Flos mundi, chronique universelle aragonaise composée en 1407, dont l'unique manuscrit connu est conservé à la B. N. de Paris, la Relation de la descendance des rois de Navarre et des autres choses remarquables du dit royaume, de Jean de JASO (Boletín de la Academia de la Historia, 24, 1894, p. 129-143)... Du début du XVIe siècle, nous n'avons pris en compte que l'incontournable De genealogia, de Lucio Marineo Sículo qui a tant de points communs avec notre Generatio. Les textes, nombreux, que nous laissons au bord du chemin sont de différente nature et d'intérêt divers. Peu d'entre eux ont jouit d'autorité dans l'historiographie de l'Espagne orientale. Les repères dont nous avons jalonné notre parcours sont des textes majeurs qui recueillent largement, modifient et rediffusent le savoir qui les précède. Ils nous ont donné des indications qui, pour atteindre nos objectifs, nous ont semblé suffisamment utiles. Il reste, bien entendu, beaucoup d'incertitudes; les voies de la recherche -d'une recherche de tout autre ampleur- restent ouvertes.

${ }^{10}$ Antonio UBIETO ARTETA, éd., Crónica de San Juan de la Peña, Valencia : Textos medievales (4), 1961 (datation, p. 10-11). Version aragonaise : Carmen ORCÁSTEGUI GROS, éd., Crónica de San Juan de la Peña, Saragosse : Institución Fernando el Católico, 1986. Version catalane : Amadeu-J. SOBERANAS LLEÓ, éd., Crónica general de Pere III el Cerimoniós dita comunament Crónica de Sant Joan de la Penya, Barcelone: Alpha, 1961. Chronique de Saint-Jean de la Peña : désormais, CSJP.
} 
fonde. L'affinité est patente dès le système que le sommaire propose pour les premiers temps : Garsias Jimenez - Garsias Iñiguez - Fortuné Garsias - Sanche Garsias - (Jimeno Garsias, pour CSJP); extinction de la lignée, puis arrivée en Navarre et érection en prince (ou en roi) d'Iñigo Arista" ${ }^{11}$. Cette construction, manifestement aberrante, qui croise les dynasties «Jimena» et «Iñiga» des Généalogies de Roda ${ }^{12}$ dans le même temps qu'elle les dissocie dans la chronologie, prétendant que la seconde succède à la première après que celle-ci s'est éteinte, distingue CSJP et sa tradition de l'historiographie navarro-aragonaise antérieure ${ }^{13}$. L'affinité est sensible tout au long du sommaire historique, notamment dans la grande bifurcation qui, le lecteur parvenu à la descendance de Sanche le Grand, lui fait abandonner le suivi des voies dynastiques de Navarre et de Castille pour aller le seul chemin des successions aragonaises. Notre texte, enfin, comme le mouvement composé par les vingt-et-une premières divisions de CSJP, accorde un important développement final à l'accord de partage politique conclu entre Ramire le Moine et Garsias Ramirez. Cet accord, dit de Vadoluengo, n'est pas attesté par la documentation et trouve dans CSJP sa première mention historiographique.

Entre notre sommaire et CSJP, il est, cependant, de nombreuses différences. Les datations sont rarement les mêmes. Conquête de l'Espagne par les Sarrasins : 667 au lieu de $713^{14}$; élection royale de Garsias Jimenez : 708 au lieu, semble-t-il, de 758 (CSJP version aragonaise) ou de 858 (CSJP versions latine et catalane); mort de Garsias Jimenez : 758 au lieu de 891; mort de Garsias Iñiguez : 802 au lieu de 903; mort d'Iñigo Arista : 864 au lieu de 839 (CSJP version aragonaise); mort de Garsias Iñiguez II : 881 au lieu de 861; mort de Sanche Garsès «Abarca» : 936 au lieu de 905; mort de Garsias Sanchiones : 964 au lieu de 930; mort de Pierre Ier : 1109 au lieu de 1125; mort de Ramire II : 1139 au lieu de 1136. Seules coïncident dans les deux textes, les dates de mort de Ramire Ier (1063) et de Sanche Ramirez (1094). La plupart de ces dates, il est vrai, varient encore dans les Généalogies de Roda, les Chroniques navarroaragonaises, le Liber regum, le For général de Navarre puis, dans le sillage de CSJP, la Chronique de Jacques Domenech (à quelques exceptions près, cependant), les Histoires

${ }^{11}$ UBIETO, p. 27-33.

${ }^{12}$ Cf. José María LACARRA, «Textos navarros del Códice de Roda», Estudios de Edad Media de la Corona de Aragón, 1, 1945, p. 193-284 (notamment, p. 208 et 229-239). CSJP simplifie et remodèle le propos généalogique, complexe et obscur, des Généalogies de Roda.

${ }^{13} \mathrm{La}$ Chronica najerensis -composée sous domination castillane de la Rioja, mais très au fait de l'histoire navarraise- distingue les deux lignées fondatrices lorsqu'elle remonte aux origines de Sanche le Grand [UBIETO, Crónica najerense, Valencia : Anubar (Textos medievales, 15), 1966, p. 90]. Par la suite, la plupart des historiens navarrais -l'auteur anonyme du Liber regum, le Navarrais Rodrigue Jimenez de Rada, Charles, prince de Viana, notamment- feront simple en commençant leur généalogie par Iñigo Arista. Dans la couronne aragonaise, au contraire, Jacques Domenech et ses successeurs (Pierre Tomich, Marineo Sículo, Étienne Rollán, etc.) reproduiront l'entier du système forgé par CSJP.

${ }^{14}$ Le For général de Navarre donnait cependant «era de DCC et dos años», soit l'année 664 (ILLAREGUI, p. 1) et, au début du XVIe siècle encore, Lucio Marineo Sículo datera l'événement de l'an $617\left(\right.$ De genealogia , fol. $\left.3 \mathrm{v}^{\circ}\right)$. 
de Tomich, la Chronique de Charles, prince de Viana, la Chronique de Vagad, le De genealogia de Sículo... D'une certaine façon, il s'agit là d'un trait caractéristique de l'historiographie de l'Espagne orientale sur lequel, du reste, on s'étonne que les spécialistes ne se soient pas penchés.

D'autres différences atteignent, plus profondément, la signification du propos historique. Relativement à CSJP, notre sommaire affirme avec plus de force et exalte l'origine proprement aragonaise des rois d'Aragon.

Le caractère radical de la royauté navarraise est atténué. Garsias Jimenez, nous l'avons vu, est élu roi «dans la province d'Aragon» par les chrétiens réfugiés à SaintJean de la Peña, dans les monts d'Oroel. Il conquiert ensuite une grande partie des terres navarraises et c'est seulement son fils, Garsias Iñiguez, qui, le premier, et du reste après avoir conquis Pampelune, prend le titre de «roi de Navarre». A propos de Garsias Jimenez, CSJP, parallèlement au récit qu'elle faisait de la fondation «en terres aragonaises» ${ }^{15}$ de Saint-Jean de la Peña, déclarait qu'il «régnait en Navarre», évoquant, en Aragon, la domination du comte Aznar ${ }^{16}$. Elle ne disait rien des conquêtes de Garsias Jimenez ni de celle de son fils Garsias Iñiguez. Ce dernier était seulement montré «régnant à Pampelune» ${ }^{17}$. En 1380, Jacques Domenech ${ }^{18}$, inquisiteur de Majorque et du Roussillon et auteur, à la demande de l'infant Jean (futur Jean Ier d'Aragon), du premier remaniement de CSJP, fait un pas encore timide dans le sens d'un accès précoce de l'Aragon au statut de royaume. Conservant la souche navarraise, il élargit l'implantation territoriale du pouvoir de Garsias Jimenez : celui-ci, après avoir conquis Pampelune, devient, le premier, roi en terres pyrénéennes, mais il domine aussi l'Aragon grâce au vasselage du comte Aznar. Aussi bien Domenech peut-il déclarer successivement que Garsias «cepit regnare in Navarra» et le qualifier de «primus rex Navarre et Aragonie» ${ }^{19}$.

15 UBIETO, p. 25 et 26.

${ }^{16}$ Ibid., p. 24-28. Dans CSJP, le groupe des premiers chrétiens réfugiés sur les terres de Panon -où un hermite fonde, sous le vocable de saint Jean Baptiste, une petite église qui deviendra Saint-Jean de la Peña- est entièrement détruit par les troupes d'Almanzor. CSJP, après avoir rapporté les origines du saint lieu, indique seulement : «Et tunc temporis regnabat in Nauarra rex Garcias Eximini et regina Eneca uxor sua. Et in Aragonia dominabatur comes Azenarius» (ibid., p. 27).

${ }^{17}$ Ibid., p. 28 : «Post mortem regis Garcie Eximini regnauit Pampilone rex Garcias Eneci, anno Domini dccc, nonagesimo primo». Pour Garsias Jimenez, voir note antérieure.

18 Pedro LóPEZ ELUM, éd., Jaime DOMENECH, Cronica, Valencia : Anubar (Textos medievales, 42), 1975. Désormais : Cronica.

${ }^{19}$ Cronica, p. 54-55 : «Qui vero illam cladem effugere potuerunt, recollegerunt se in fortissimis montibus et petrarum seu rupium abruptis, nemorumque densitate opacis, ubi multo tempore construentes castra et fortalicia se deffenderunt. In tantum quod dicti montes numquam per serracenos capi potuerunt. Scilicet in montibus Rippacurcie, Subarbi, Biorrore, Aragonie, de Archedia, de Ordonya, de Alava, de Hiposcoa, de Asturiis et de Viscanya. Et elegerunt supra se rectores seu gubernatores qui eos deffenderent et gubernarent. Unde illi de Asturiis prefecerunt Pelagium, virum strenuum, qui, recuperata civitate Legionis de manu serracenorum, regem Legionis se intitulavit. Et pari modo ceteri christiani per iuga montis Pirinei vagantes rectores sibi proposuerunt. Sed quos et ubi non repperi usque ad annum Domini dccclviii, sub quo anno cepit regnare in Navarra Garcia Ximenis. Et bene verum quod in supradictis terris erant comites, sicut in Rippacurcia et in Subarbi et in Aragoniam et in Castella, et parimodo in Navarra et in aliis porcionibus terrarum, que dominium serracenorum effugere potuerunt. [...] Qualiter vero dictus Garcia Ximinis fuerit rex constitutus non inveni clare. Puto tamen quod sicut in aliis partibus, in quibus se 
Dans ses Histoires et conquêtes des rois d'Aragon et des comtes de Barcelone ${ }^{20}$, achevées en 1448, le très catalaniste Pierre Tomich Cauller va plus loin en déplaçant de la Navarre au Sobrarbe et au Ribagorza le royaume primordial de Garsias Jimenez. D'autre part, et comme dans notre texte, Garsias est élu roi par les chrétiens réfugiés à Saint-Jean de la Peña ${ }^{21}$. Assez paradoxalement, ceci n'empêche pas l'historien catalan d'affirmer, une fois parvenu à Garsias Iñiguez : «Mort donc le roi Garsias Jimenez, son fils appelé Garsias Iñiguez fut roi, lequel, après son père, prit le titre de roi de Navarre» Tomich, néanmoins, se rapproche à nouveau de notre sommaire lorsqu'il précise (sans se soucier davantage de cette seconde contradiction) que Garsias Iñiguez prit ce titre «parce qu'en peu de temps il avait conquis Pampelune»². Pour Charles de Viana, prince héritier du royaume de Navarre et auteur, en 1454, d'une chronique de ses rois ${ }^{23}$, le «premier roi de Navarre» est Iñigo $\operatorname{Arista}^{24}$. Les précédents restent néanmoins strictement navarrais, puisque Garsias Jimenez est regardé comme «le comte de l'ancienne Navarre» ${ }^{25}$. A l'opposé, dans la Chronique d'Aragon ${ }^{26}$ qu'il semble avoir composée au long des années 1465-1499, l'Aragonais Gaubert Fabrice de Vagad va plus loin dans le sens de Tomich et d'«autres chroniqueurs ${{ }^{27}}^{27}$ dont il se réclame. Démentant

christiani tutaverant, aliquos vel comites vel dominos sibi prefecerant in montibus supradictis. Ex quibus dictus Garcias, recuperata Pampilona ab infidelibus, regem primo se nominavit, quemadmodum fecerat Pelagius Legionensi civitate obtenta. Erat tunc comes in Aragoniam sive ante sive post dicto Garcie, subiectus et eius vasallus. Vocabatur autem dictus comes Aznarius [...]. Primus igitur rex Navarre et Aragonie quantum ad altum dominum fuit Garcia Ximinis.»

20 Pere TOMICH, Histories e conquestes dels reys d'Arago e comtes de Catalunya, Valence : Anubar (Textos medievales, 29), 1970 (fac-similé de l'impression de 1534), fol. $9 \mathrm{r}^{\circ} \mathrm{b}$. Désormais : Histories.

${ }^{21}$ Histories, fol. $7 \mathrm{v}^{\circ} \mathrm{b}-8 \mathrm{r}^{\circ} \mathrm{a} \ll[\ldots]$ e apres la spluga fou recobrada per los Chrestians de munt Oriel qui eren en nombre ccc Chrestians : e per aquesta raho la dita Spluga fou enfortida e murada : e apres poch temps que los Chrestians la hagueren murada venc aqui en la coua vn hermita sanct hom appellat Johan : qui feu aqui vna iglesia sots inuocacio de sanct Johan Babtista : e sobre aquella coua hauia y vna gran penya de roca : e per raho daquesta penya los Chrestians appellauen aquesta coua la coua de sant Johan de la penya : axi com vuy es appellada leuantli lo nom de Panno. E apres lo dit hermita troba aqui en la muntanya dos cauallers sants homens : los quals la vn hauia nom Vot e laltre Phelitso los quals si eren saluats com les ditas muntanyes foren preses e corregudes per lo dit Almesor de Cordoua Rey de Osca e los Chrestians ab consell de aquells dos cauallers hagueren fet lur capita e senyor vn caualler qui era de linatge Real dels Gots appellat Graçia ximeniç : e aquell Rey fo axi bon caualler e virtuos que ab aquells pochs Chrestians se subiuga totes les muntanyes dessus ditas de Subarbia e de Ribagorça e daquelles muntanyes se intitula Rey : e apres que lo dit caualler hague pres titol de rey mori lo hermita Johan...».

22 Ibid., fol. $7 \mathrm{r}^{\circ} \mathrm{b}$ : «Capitol xiii [...] : Mort doncs lo Rey Garcia Ximenis fou Rey son fill appellat Garçia Eniego lo qual apres de son pare pres titol de Rey de Nauarra per tal com en poch temps hague conquistada Pampalona».

23 José YANGUAS y MIRANDA, éd., CARLOS, PRÍNCIPE DE VIANA, Crónica de los reyes de Navarra, Valence : Anubar (Textos medievales, 27), 1971 (fac-similé de l'édition de Pampelune : Imprenta de D. Teodoro Ochoa, 1834, avec index d'Antonio UBIETO ARTETA). Désormais : Cronica de los reyes.

24 Crónica de los reyes, p. 34.

25 Ibid., p. 35.

${ }^{26}$ Gaubert Fabrice de VAGAD,Coronica de Aragon, Saragosse, 1499. Désormais : Coronica. Datation de la Chronique d'Aragon et de ses différentes élaborations : Robert Brian TATE, Ensayos sobre la historiografía peninsular del siglo XV, Madrid : Gredos, 1970, p.267-269.

27 Coronica, fol. 8. 
ceux qui qualifient Garsias Jimenez de roi de Navarre ${ }^{28}$, il le montre élu à Oroel par les

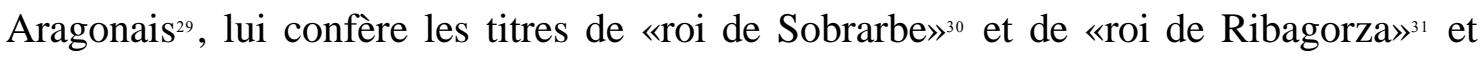

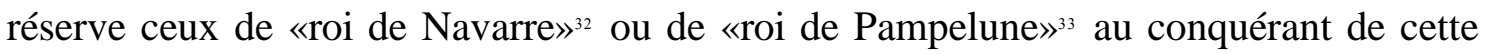
ville $^{34}$, Garsias Iñiguez. Celui-ci, toutefois, ne fait qu'ajouter ces titulatures à celles de son père ${ }^{35}$. Dans son De genealogia (achevé en 1509), Lucio Marineo Sículo, qui semble également situer à Saint-Jean de la Peña l'élection de Garsias Jimenez ${ }^{36}$, renchérit sur Vagad en privant du titre de roi de Navarre non seulement le premier fondateur mais encore tous ses descendants et même l'ensemble des représentants de la seconde dynastie royale y compris Sanche le Grand. Il proclame cependant au début du paragraphe consacré à Garsias Jimenez, dans la lignée de Tomich et de Vagad : «De Garsia Ximenio Suprarborum rege. Cui non Aragonie : sed Pyreneorum montium et Suprarbrorum regis nomen posuerunt $»^{37}$.

Notre sommaire, d'autre part, écourte à hauteur du comte Galindo la dynastie comtale aragonaise dont CSJP montrait la continuation jusqu'au fils de Galindo, Fortuné Jimenez ${ }^{38}$. Le fils et successeur du roi Garsias Iñiguez, Fortuné Garcès, peut ainsi, aussitôt après avoir épousé la fille de Galindo, devenir comte d'Aragon et associer personnellement le comté au royaume. Dès lors, tandis que dans CSJP le fondateur définitif, Iñigo Arista, était élu par «les gens de la terre en accord avec Fortuné Jimenez, comte d'Aragon $»^{39}$, ce sont ici «les Navarrais et les Aragonais» qui, ensemble et directement, érigent Iñigo en prince, la dynastie royale naissant de la décision de ces peuples assemblés dans leur geste et agissant à parité. Domenech, comme CSJP, montre l'entier de la dynastie comtale aragonaise ${ }^{40}$; mais, concernant l'élection d'Iñigo Arista, sa

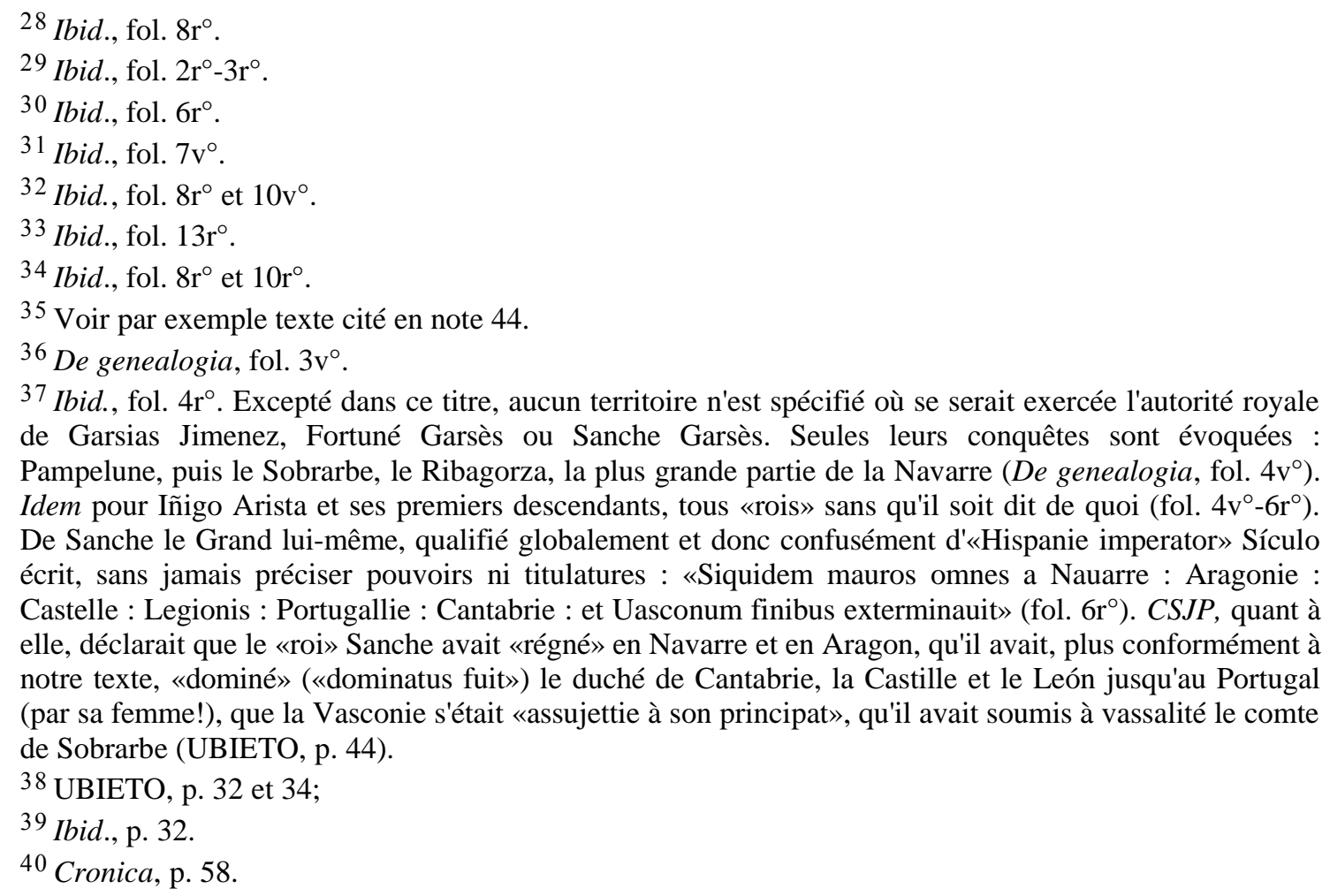


position est moyenne entre CSJP et notre sommaire : «Erat autem comes Aragonia, mortuo supradicto Galindo, Fortuyn Ximenez. Qui cum aliis nobilibus et popularibus de Navarre et de Aragonia elegerunt in regem Navarre quendam nobilem comitatus Bigorre, qui fuit appellatus Ennecus cognomento Arista» ${ }^{41}$. Charles de Viana, quant à lui, concilie CSJP et Domenech : «Cette même année, [Navarrais et Aragonais] s'étant assemblés pour l'élection du roi qui devrait les régir [...] ne trouvèrent chevalier plus vaillant ni bienheureux que le noble Iñigo Garsès [...] Et les gens de la terre, en accord avec Fortuné Jimenez, comte d'Aragon, élurent roi de Navarre le dit Iñigo Garsès ${{ }^{42}}^{2}$. Le récit de Tomich, en revanche, est, sur le fond, en tout point identique à celui de notre Generatio : «Après la mort de Garsias Iñiguez de Navarre et de Sobrarbe, son fils appelé Fortuné fut roi, et il prit pour femme la fille du comte Galindo d'Aragon... Et le comte mourut $[. .$.$] et le roi Fortuné de Navarre fut comte d'Aragon. Et de ce roi et de$ cette reine fut fils le roi Sanche Garsès, lequel régna peu de temps... Et le royaume et le comté restèrent sans héritier, et comme le rapportent les histoires de l'archevêque tolédan, par les Navarrais et les Aragonais fut élu un roi [...] appelé par son nom Iñigo....»3. Très distant de notre texte, Vagad est, sur ce point, celui qui va le plus loin dans le sens d'une interprétation favorable à l'Aragon puisque aussi bien les Aragonais embrassent tout entière l'histoire des origines. La dynastie comtale aragonaise est en fait liée d'emblée à la cour, elle-même aragonaise, de Garsias Iñiguez, dont le comte Aznar, qui conquiert l'Aragon, est issu ${ }^{44}$. Nul besoin, dès lors, ni d'écourter la dynastie au

\footnotetext{
${ }^{41}$ Ibid., p. 58-59.

${ }^{42}$ Crónica de los reyes, p. 40-41 : «Como quiera que los dichos navarros, e aragoneses, obiesen deliberado de levantar rey, como dicho es, pasaron asaz tiempo que non lo ficieron por algunas disensiones que entrellos corrian; e en el año 885, D. Iñigo Garcia, fijo de D. Jimen Iñiguez, señor de Abarzuza e de Bigorra, [...] fue en ayuda de los dichos cristianos; en el qual mesmo año, siendo ayuntados sobre la eleccion del rey que los habia de regir, considerando su grant confusion por que eran sin rey e sin cabeza, e pensando a quien esleirian por señor suyo, non fallaron mas valiente nin mas aventurado cabaillero que el noble varon D. Iñigo Garcia, el qual habia vencido, e desbaratado, muchas veces los moros; el qual, por la grant nobleza de corazon, e de armas, que en él era, las gentes de toda la tierra, a una voz, concordantes con D. Fortun Jimeniz conde de Aragon, esleyeron al dicho D. Iñigo Garcia por rey de Navarra $[\ldots] \gg$.

43 Histories, fol. $8 \mathrm{v}^{\circ} \mathrm{a}:$ : Apres la mort de aquest Garçia Eniego de Nauarra e de Subarbia fou Rey son fill appellat Furtunyo e pres per muller la filla del Comte Galindo de Arago... e [...] mori lo dit Comte [...] e lo rey Furtunyo de Nauarra fou Comte de Arago : e de aquests Rey e Reyna fou fill lo rey Sanxo Garçia lo qual regna poch temps... E romangueren los Regne e Comtat sens hereter : e segons recomtan les sues histories del gran Archabisbe Toleda per los Nauarresos : e Aragonesos fou elegit vn Rey [...] appellat per son nom Eniego...». De quelle variante du De rebus Hispaniae disposait Tomich? Invente-t-il? L'oeuvre du Navarrais Rodrigue Jimenez de Rada, telle qu'elle nous est connue, dit ceci : «Cum enim Castella, Legio, et Navarra variis Arabum incursionibus vastarentur, vir advenit ex Bigorciae Comitatu, bellis et incursibus ab infantia assuetus, qui Enecho vocabatur, et quia asper in proeliis, Arista agnomine dicebatur, et in Pyrenaei partibus morabatur, et post ad plana Navarrae descendens, ibi plurima bella gessit : unde et inter incolas regni meruit principatum» [María Desamparados CABANES PECOURT, éd., Rodericus XIMENIUS de RADA, Opera, Saragosse : Anubar (Textos medievales, 22), 1985, p.112a].

${ }^{44}$ Coronica, fol. $13 r^{\circ}$ : «Dela corte del esclarecido principe y alto rey don Garci Yñigo : salio aquel magnanimo y generoso cauallero godo don Aznar primer conquistador de Aragon. ca reynando en sobrarbe : y en ribagorça : y pamplona : el poderoso rey don Garci Yñigo amanecio entre los suyos el denodado cauallero don Aznar...». Au vrai, Vagad ne fait qu'associer plus étroitement à la cour royale un
} 
niveau de Galindo, ni même d'un mariage -sur la réalité duquel Vagad se montre réservé $^{45}$ - entre Fortuné Garsès et la fille de Galindo. Quant à Iñigo Arista, son histoire reproduit celle que Vagad avait tracée pour Garsias Jimenez et son fils : Iñigo est élu roi de Sobrarbe avant de s'intituler roi de Navarre; aucune place n'est faite aux Navarrais dans une élection dont seuls sont responsables les Aragonais ${ }^{46}$. Marineo Sículo -pour qui la dynastie comtale s'éteint aussi avec Galindo ${ }^{47}$ - affirme d'abord, comme Vagad, qu'Iñigo Arista fut élu roi par les Aragonais («Et Aragones Ennicum cui Arista cognomen erat $[. .$.$] sibi regem delegerunt») avant de déclarer, rejoignant à nouveau$ Tomich et notre texte, qu'il fut érigé en prince par Navarrais et Aragonais : «Ennicus Arista rex electus vir et manu promptus : et in armorum certaminibus ardens [...] ex montibus Pyreneis cum exercitu descendens maurorum magnas copias deleuit : et uictor in Nauarram peruenit : vbi princeps a Nauarris et Aragonibus eligitur $\rangle^{48}$.

Dernier point fort de cette orientation, la mort de Garsias de Navarre au cours d'une guerre avec Sanche Ramirez et la soumission consécutive des Navarrais au roi d'Aragon. Toute la tradition hispanique antérieure à CSJP -léonaise et castillane, certes, mais également navarro-aragonaise- s'accordait à montrer la victime tombant sous les coups de Ferdinand Ier de Castille à Atapuerca et la Navarre passer en partie sous le contrôle du Castillan. Elle montrait ensuite le reste du royaume navarrais soumis à la royauté aragonaise après l'assassinat du fils de Garsias, Sanche dit «de Peñalén» CSJP, soucieuse seulement de suivre les successions royales aragonaises, ne disait rien des circonstances de la mort de Garsias ${ }^{50}$. Domenech suit $C S J P^{s_{1}}$, le prince de Viana s'ajustant quant à lui de plus près à la tradition castillane du De rebus Hispaniae et de l'Histoire d'Espagne ${ }^{s_{2}}$. Vagad reste lui-même fidèle à la tradition dominante ${ }^{s_{3}}$. A nouveau, la première occurrence datable d'une vision approchante des faits est un

homme que Tomich montrait déjà, issu du groupe des premiers réfugiés, partir à la conquête de l'Aragon : «E enlo temps de aquest Rey [Garcia Ximenis] se leua vn caualler qui appellauen per son nom Albuar e ab vna partida de aquells Chrestians passa lo riu qui es appellat Arago apres ( sic) la ciutat de Jaca e altres vilas e Castells que tenien los Moros : e esser passat aquell riu torna tot lo que pres hague ala fe chrestiana : lo caualler hauent conquitades les ditas terras se intitula : e pres titol de Comte e feu se appellar Comte de Arago prenent lo nom de aquel riu.» (Histories, fol. 8r ${ }^{\circ} \mathrm{b}$ ).

45 Ibid., fol. 14 : «[D. Aznar houo] vn noble fijo que llamaron el conde don Galindo, que succedio enel condado a su padre [...] y ahun quieren otros dezir : que este conde tan magnifico don Galindo no teniendo mas de sola vna fija. que trato de la dar por muger al esclarecido y magnanimo rey don Fortun Garcez. porque el condado passasse en reynado. y que el rey con su fija gozassen del señorio de toda la tierra. verdad sea : que otras coronicas ponen : que houo muchos mas condes en Aragon...»

46 Ibid., fol. 16.

${ }^{47}$ De genealogia, fol. $4 \mathrm{v}^{\circ}$.

48 Ibid., fol. $4 \mathrm{v}^{\circ}$.

${ }^{49}$ Georges MARTIN, Les juges de Castille. Mentalités et discours historique dans l'Espagne médiévale, Paris : Klincksieck (Annexes des CLHM, 6), 1992, p. 122, 139, 171-172, 241 (n. 73), 261-262, 268, 278$280,456$.

50 UBIETO, p. 53 : «Sciendum est quod mortuo Garcia rege Nauarre superfuerunt sibi duo filii...».

51 Cronica, p. 72.

52 Crónica de los reyes, p. 63-64.

${ }^{53}$ Coronica, fol. $25 \mathrm{r}^{\circ}$. 
passage (au demeurant moins clair) des Histoires de Tomich, où celui-ci écrit à propos de Sanche Ramirez : «il fut très bon roi, car il fit la guerre au roi de Castille et au roi de Navarre, et après cette guerre le roi de Navarre mourut et les Navarrais le prirent pour roi $\aleph^{54}$. Mais il faut encore attendre le De genealogia de Sículo pour trouver une déclaration aussi précise que celle de notre texte : «Deinde bellum quoque gessit [Santius Ramirus] cum Garsia patruo rege Nauarre : quem vicit et occidit : et a Nauarre totium populis rex appellatur est iuratusque $»^{55}$.

L'identité aragonaise, qui se consolide aux dépens de la Navarre, s'affirme aussi face à la Catalogne. C'est sans doute ainsi qu'il faut comprendre l'achèvement du sommaire sur le règne de Ramire le Moine, dernier descendant d'Iñigo Arista par les mâles. Pour CSJP comme pour sa première filiation, la mort de Ramire II, à la suite de quoi la lignée royale fondée par Iñigo Arista s'associait par une femme (Pétronille, fille de Ramire et d'Agnès du Poitou) à celle des comtes de Barcelone pour se prolonger désormais en elle, marquait en effet une mutation dynastique de la plus haute importance que la plupart des historiens, donnant «fin et achèvement aux rois d'Aragon $»^{56}$, regardaient comme une sorte d'aliénation finale du royaume aux comtes catalans. L'achèvement de notre sommaire isole de même le socle primordial, proprement aragonais, d'une royauté destinée à fédérer, à partir du XIVe siècle et surtout au XVe, les territoires les plus divers.

Quant à l'exaltation qui, cette fois, opère même relativement à l'Espagne occidentale, elle tient aussi bien à l'effacement de la bâtardise de Ramire Ier et donc à son institution en fils aîné légitime de Sanche le Grand -«Ex prima muliere [Sanctius Maior] habuit filium Ranimirum et ex secunda habuit tres filios», et plus loin «[Ranimirus] filius Sanctii maioris ex prima uxore»- qu'à l'affirmation de l'ascendance gothique de Garsias Jimenez, premier roi élu par les chrétiens d'Aragon.

En ce qui concerne Ramire, à peu près toute l'historiographie hispanique médiévale -y compris CSJP, Domenech, Tomich et Charles de Viana- le tenait pour un

\footnotetext{
${ }^{54}$ Histories, fol. $9 \mathrm{v}$ b : «[...] fou molt bon Rey : car hague guerra ab lo Rey de Castella e ab lo rey de Nauarra : e apres de aquesta guerra lo Rey de Nauarra mori e los Nauarresos prengueren lo per Rey».

${ }^{55}$ De genealogia, fol. $7 \mathrm{v}$.

56 «Regum Aragonum tractaui hic finem imponimus. Et quia regnum Aragonum deficiente in eo herede masculo, per contractum matrimonii, peruenit ad comitem Berchinone. Quis fuit primus comes Barchinone et quomodo gradatim ab eo alii descenderunt et que fuit eorum uita dicamus.» (UBIETO, $\mathrm{p}$. 99-100). Cette articulation est soulignée de même par Jacques Domenech dans son introduction à la généalogie des rois de Navarre et d'Aragon : "Quia igitur intencionis mee est in presenti opusculo generacionem regum Aragonie breviter texere, dicti vero reges ad modum Iordanis, qui ex duobus fontibus, scilicet, Ior et Dan oritur, et conuenti in unum fluvium coalescunt ex duplici fonte, scilicet quantum ad regnum a regibus qui in Navarra et Aragonia principabantur, quantum autem ad principatum Cathalonie a comitibus Barchinone originem traxerunt, et dictis principatibus per matrimonium unitis unum dominum effecerunt. Idcirco lineam duplicem, scilicet regum et comitum usque ad unionem regni et comitatus, nos ordiri opportet» (Cronica, p. 53-54). Tomich donne pour titre à son treizième chapitre : «Qui tracta com hague Rey en Arago : e perque rey pres titol de Realme : e quants Reys hi ha haguts finis que lo regne peruench a vna filla del derrer Rey : que fou muller del egregi Comte de Barçelona» (Histories, fol. $\left.7 \mathrm{r}^{\circ} \mathrm{b}\right)$.
} 
fils naturel engendré par Sanche le Grand avant son mariage avec la comtesse de Castille. La «légende de la reine calomniée» avait même été inventée pour justifier la donation de l'Aragon à ce bâtard ${ }^{57}$. Seuls s'ajustent sur ce point à notre texte Vagad -qui revendique hautement la légitimité de Ramire et donne à sa mère le nom de Gaya de Ayuarss - et Sículo qui, comme souvent, accouple deux traditions sans se soucier de les concilier. Agençant d'abord les versions de Jimenez de Rada et de Vagad il déclare : «[Santius maior] uxorem duxit Eluiram feminam nobilissimam : cuius erat castrum Aiuaris. Ex qua filium progenuit nomine Ramirum : qui [...] fuit rex Aragonie primus. Ceterum Eluira defuncta Santius aliam duxit vxorem Castelle comitis filiam : que Maior dicebatur. De qua tres illi filii nati fuere : Garsias : Ferdinandus : et Santius $»^{59}$. Puis il écrit, reprenant cette fois la leçon de CSJP, que Sanche «[Ramirum] filium et haeredem legitimum adoptauit $\gg^{60}$.

Pour ce qui est de Garsias Jimenez, si la volonté de mettre sur un pied d'égale dignité les royautés post-wisigothiques de León et de Pampelune est sensible dès la Chronique de Jacques Domenech ${ }^{61}$, les Histoires de Pierre Tomich consituent le premier exemple d'un mythe néo-wisigothique attaché à ce roi et, ici encore, la première similitude datable (1448) avec notre sommaire. Tomich, au demeurant, va plus loin que

\footnotetext{
${ }^{57}$ Pour l'historiographie castillane, navarraise et catalane des XIIe et XIIIe siècles, cf. G. MARTIN, Les juges de Castille..., p. 95-96 (n. 119) et 281. CSJP : UBIETO, p. 44-47; Domenech : Cronica, p. 66; Tomich : Histories, fol. $9 \mathrm{v}^{\circ}$ a; Charles de Viana : Crónica de los reyes, p.55-60.

58 « Fue dos vezes casado este magnanimo y pujante rey. Caso la primera : con doña Gaya : muy illustre señora dela villa de aynar (sic) : y de muchas tierras en aragon. Flor del mundo : assi lo aueriga. que es vna luenga : y famosa coronica» (Coronica, fol. 20v $)$; «Aqui doy vozes y me quexo yo dela tan enconada y aleuosa inuidia delos passados que pudo tanto tiempo encubrir la tan alta y tan generosa limpieza del tan illustre y tan legitimo infante don Remiro, que muchos coronistas por lo ignorar le diffamaron de ser bastardo : mas no por cierto el arçobispo de toledo que nunca le llamaua saluo fijo de otra madre» (Coronica, fol. $21 \mathrm{r}^{\circ}$ ). Les références de Vagad au Tolédan sont plus fiables que celles de Tomich. Elles n'en sont pas pour autant exemptes de parti pris. Jimenez de Rada distingue bien ainsi Ramire de ses frères : «Ranimirus [...] Regis Sancii filius, non ex illa qua alii ortus matre». Mais il écrit aussi un peu plus loin, établissant la naissance hors mariage du futur roi d'Aragon : «[...] Ranimirus principium fuit Regum qui in Aragonia regnaverunt... Fuit itaque Ranimirus filius Regis Sancii qui dictus est Maior, quem suscepit ex quadam nobilissima domina de castro Aivarum» (CABANES PECOURT, respectivement $\mathrm{p}$. $116 \mathrm{~b}$ et $117 \mathrm{a})$.

${ }^{59}$ De genealogia, fol. $6 \mathrm{r}^{\circ}$. Pour les matériaux de la première construction des faits, voir note antérieure. Habilement, Sículo distribue entre les deux femmes deux noms prêtés par le Tolédan -CSJP et une longue tradition historiographique- à la comtesse de Castille («Maior vel Geloira», CABANES, p. 113b).

${ }^{60} \mathrm{Ibid}$., fol. $6 \mathrm{v}^{\circ}$. CSJP : UBIETO, p. $47:$ :Et fuit adoptatus in filium et hereditatus in regno Aragonum dictus Remirus».

${ }^{61}$ Cronica, p. 54-55. Notamment : «Garsias, recuperata Pampilona ab infedilibus, regem primo se nominavit quemadmodum fecerat Pelagius Legionensi civitate obtenta», p. 55. Domenech, cependant, ne croit pas en une continuité néogothique : «Unde illi de Asturiis prefecerunt Pelagium, virum strenuum, qui, recuperata civitate Legionis de manu sarracenorum, regem Legionis se intitulavit. Et pari modo ceteri christiani per iuga montis Piranei vagantes rectores sibi proposuerunt. Sed quos et ubi non repperi usque ad annum Domini DCCCLVIII, sub quo anno cepit regnare in Navarra Garcia Ximenis. Et bene verum quod in supradictis terris erant comites, sicut in Rippacurcia et in Subarbi et in Aragoniam et in Castella, et parimodo in Navarra et in aliis porcionibus terrarum, que dominium serracenorum effugere potuerunt. Nec est dubium quod predicta dominia comitum per electionem et non per succesionem provenerunt. Quia re vera de Gothis qui primitus in Hispania dominabantur aut pauci aut nulli post devastaciones dictarum terrarum remanserunt».
} 
celui-ci puisque, dans son opinion, Garsias Jimenez n'était pas seulement d'origine gothique, mais appartenait en outre «au lignage royal des Goths» ${ }^{62}$. Dans le dernier tiers du XVe siècle, Vagad reprend le propos de Tomich $^{63}$ mais prête également une origine gothique à Iñigo Arista, véritable fondateur de la dynastie régnante ${ }^{64}$. Au début du XVIe siècle, Marineo Sículo s'accorde avec notre Generatio, et non avec Tomich, en ce qui concerne Garsias Jimenez -«ex stirpe Gothorum» ${ }^{65}$. En revanche, il suit Vagad lorsqu'il donne -«ex gothica gente»- la même origine à Iñigo Arista ${ }^{66}$.

Notre sommaire historique a donc de nombreux points communs avec une représentation des origines de la royauté aragonaise dont on peut suivre la mise en place en Catalogne et en Aragon entre les années centrales du XVe siècle et la première décennie du XVIe. Les oeuvres qui la portent servent communément la dignité politique de l'Espagne orientale, mais notre sommaire a des sympathies particulières avec celles qui infléchissent le récit de CSJP dans un sens favorable au royaume aragonais. Au sein de ce mouvement de reconfiguration du passé, les analogies sont fortes notamment avec les conceptions de Tomich (1448), de Vagad (1465-1499) et, plus encore, avec celles de Marineo Sículo (1509). Notre sommaire, cependant, ne donne point dans les débordements anti-navarrais des derniers et, en structure, est plus proche des premières esquisses. Son aragonisme a beau être patent, l'enracinement traditionnel des rois d'Aragon dans la royauté navarraise demeure. Garsias Jimenez est élu «in provincia Aragonie» et n'est pas roi de Navarre. Mais notre texte n'en confère pas moins volontiers le titre de «rex Navarre» aux rois fondateurs et respecte la préséance navarraise dans leur titulature ou l'énumération des territoires qui sont en leur pouvoir : «fuit rex Navarre, Suprarbii et Ripacurcie et comes Aragonie», «successit in Navarra, Aragonia et Castilla», «dominatus est Navarram, Aragonia, Castillam, Portugaliam»...

Un dernier élément donne sa couleur particulière au parti pris aragoniste du Generatio Regum Aragonum : une «légende d'Iñigo Arista» selon laquelle, pour être élu, celui-ci aurait dû accorder les Fors d'Aragon, l'institution du Justicia mayor et le Privilège de l'Union. Il s'agit là du paradoxe le plus criant de notre texte, absent, bien entendu, de tout le corpus historiographique espagnol antérieur à la promulgation des Fors (1247), à la réforme des fonctions du Justice (1265-1266) et à la concession du Privilège de l'Union (1288). La légende, certes, relève du souci plus général, sensible chez plusieurs historiens de l'Espagne orientale, notamment navarrais et aragonais, de

${ }^{62}$ Histories, fol. $7 \mathrm{r}^{\circ} \mathrm{a}$. Texte cité en note 21.

${ }^{63}$ Coronica, fol. $3 \mathrm{r}^{\circ}$ : «un Goth royal, issu du sang des rois goths» (texte espagnol cité en note 71 ).

${ }^{64}$ Ibid., fol. $16 \mathrm{r}^{\circ}:$ : On tient [Iñigo Arista] pour un Goth, et pour un homme né du sang des Goths» («le conoscen por godo y por varon que de sangre de godos truxo su naçimento»). Dans l'univers de Vagad, Aznar, premier comte d'Aragon, est lui aussi un Goth (fol.13r ${ }^{\circ}$; texte cité en note 44).

${ }^{65}$ De Genealogia, fol. 3v $\mathrm{v}^{\circ}$ : «Anno christianae salutis decviij Garsiam Ximenem ex stirpe Gothorum virum strenuum sibi regem contra mauros elegerunt».

${ }^{66}$ Ibid., fol. $4 \mathrm{v}^{\circ}$ : «Aragones Ennicum cui Arista cognomen erat : ex gothica gente [...] sibi regem delegerunt». 
faire remonter au plus loin leurs fondations institutionnelles. Le prologue du For général de Navarre, sous ce rapport, est déjà très parlant, qui, dans le dernier quart du XIIIe sècle, déclare que l'établissement des fors précéda l'élection du premier roi d'Espagne $^{67}$. Cependant, ni CSJP ni Domenech, ni même Tomich, sur une période couvrant le dernier tiers du XIVe siècle et le première moitié du XVe, ne sont très éloquents ni a fortiori inventifs en ce domaine. Ils se contentent communément -Tomich donnant toutefois plus d'actualité au propos- de faire valoir, sur la base d'une mauvaise interprétation de ses sources par CSJP, l'activité législative de Sanche le Grand ${ }^{68}$. C'est seulement dans la seconde moitié du XVe siècle que l'on voit le thème institutionnel reverdir dans l'historiographie. Charles de Viana renoue, en 1454, avec la mythologie du For général. Toutefois, il recentre plus strictement sur l'aire navarro-aragonaise l'établissement des fors et fait d'Iñigo Arista (pour lui, Iñigo Garsias) le premier roi à jurer de les respecter : «[(Navarrais et Aragonais) élurent le dit Iñigo Garsias roi de Navarre], et lui firent reconnaître sous serment les fors établis par eux». Le prince ajoute : «Iñigo Garsias, premier roi de Navarre et seigneur d'Aragon, fit quelques conquêtes sur les Maures, aima les gentilshommes (fijosdalgo) et maintint grande justice» ${ }^{69}$. Fors, intérêts des gentilshommes et justice : les trois fondations retenues par notre légende ressortissent aux catégories exploitées par le prince de Viana dans son portrait d'Iñigo Arista. Nous sommes loin, cependant, de la précision de notre texte. Vagad, en revanche, s'en approche davantage. Dans un Épilogue des rois d'Aragon composé, semble-t-il, entre 1461 et 1479, il écrit en effet, non pas, il est vrai, d'Iñigo Arista mais $\mathrm{du}$ fondateur de la première dynastie royale, Garsias Jimenez, qu'il institua le Justice d'Aragon ${ }^{70}$. Quant à sa Chronique, elle montre ce même roi et le Justice conjointement élus par les Aragonais ${ }^{71}$ et comporte, à la suite de cette évocation, un éloge du régime

${ }^{67}$ Pablo ILARREGUI et Segundo LAPUERTA, éd., Fuero general de Navarra, Pampelune : Imprenta Provincial, 1869, p. 1-2 : «[El apostóligo Aldebano et ombres de Lombardia et de Francia] enbiáronles dizir que oviessen rey por qui se caudeyllassen; et primeramente que oviessen lures establimientos jurados et escriptos; et ficieron como los conseyllaron, et escrivieron lures fueros con conseio de los lonbardes et franceses, quoanto eyllos meior podieron como ombres que se ganavan las tieras de los moros; et despues esleyeron rey á D. Pellayo qui fué del linage de los godos...».

${ }^{68}$ CSJP : «Post mortem siquidem dicti Garcie, successit eidem Sanctius eius filius, qui duxit in uxorem quandam filiam Sancti, comitis Castelle, vocatam Mayor uel Geloyra a quibusdam. Et hic constituit bonos foros, nam usque illud tempus omnia que fiebant in terris suis iudicabantur arbitrio presidentium» (UBIETO, p. 43). Domenech : «Et statuit leges appellatus furos, quia usque ad ipsum omnia iudicabantur ad arbitrium dominorum seu presidencium in terris illis» (Cronica, p. 65). Tomich : «[...] e aquest Rey feu leys en los regnes aqui diuen furs : ab que los dits regnes son regits» (Histories, fol. $\left.9 \mathrm{r}^{\circ} \mathrm{b}-\mathrm{v}^{\circ} \mathrm{a}\right)$. Cette donnée semble avoir son origine dans une confusion -volontaire ou involontaire- entre Sanche le Grand et le comte Sanche de Castille, son beau-père, traditionnellement connu, en Castille et en Navarre (Chroniques navarraises, Liber regum), comme celui «qui donna les bons fors».

${ }^{69}$ Crónica de los reyes, p. 41-42 : «[...] esleyeron al dicho D. Iñigo García por rey de Navarra, al qual ficieron jurar los fueros por eillos establescidos; el qual D. Iñigo García, rey primero de Navarra e seiñor de Aragon, fizo algunas conquistas sobre los moros, amó los fijosdalgo e mantubo mucha justicia».

70 TATE, Ensayos, p. 269 et p. 312, § 41 : «Como rey que tiene amor/ a virtud y no a maliçia,/ por si usase de rigor/ quizo que huviesse un Justiçia/ entre el reino y su señor.»

${ }^{71}$ Coronica, fol. $3 \mathrm{r}^{\circ}$ : «escogieron juntamente y de vn golpe mismo al magnanimo varon don Garcia Ximenez godo real : y de sangre de reyes godos venido : y al official que llamaron despues justicia de 
fondé sur les fors d'Aragon ${ }^{72}$. Dans le regard que porte Vagad sur ces temps fondateurs, rien, cependant, qui ait trait à l'Union. C'est que sur cette question il a résolu de rendre plus fidèlement les faits à la mémoire historique afin d'exalter le comportement juste et exemplaire des unionistes sous les règnes de Pierre III, Alphonse III et Pierre IV ${ }^{13}$. Nulle légende d'Iñigo Arista, certes, mais les messages fondamentaux sont là. Au demeurant, la voix de Vagad, sur ces questions, n'est ni solitaire ni inaugurale. En 1435, le Justice Jean Jimenez Cerdan déclarait déjà que «ceux qui [avaient conquis] l'Aragon [avaient décidé] d'élire un roi, mais aussi qu'il y eût un juge entre lui et eux qui s'appelât Justice d'Aragon», ajoutant même que, selon certains, «le Justice [avait été] élu avant le roi» ${ }^{74}$. $\mathrm{Au}$ sein de la tradition historiographique, néanmoins, c'est encore une fois Marineo Sículo qui se rapproche le plus, quoique incomplètement et en termes plus flous, de notre sommaire lorsqu'il écrit : «[Ennicus Arista] princeps a Nauarris et Aragonibus eligitur : propositis tamen nonullis conditionibus : vt in eos equis legibus vteretur. A quibus etiam iudex : qui medius inter eos esset : petebatur : et Aragonie iusticia vocaretur» ${ }^{75}$. Affinité certaine avec notre texte. Mais celui-ci se distingue du $D e$ genealogia par sa référence à la concession du Privilège de l'Union, qu'il place sur le même plan que l'institution des Fors et du Justice. Le silence de Sículo comme, au contraire, l'intarissable éloquence de Vagad ont la même cause et nous informent mêmement du sens de notre sommaire historique.

Face à la royauté, l'Union fut l'instrument de la noblesse aragonaise et, secondairement, des élites valenciennes. Longtemps, ni les historiens catalans ni les historiens royaux aragonais ne furent portés à en exalter les vertus. Domenech condamne : «Uniones nephandas regnorum Aragoniae et Valencie contra ipsum regem [il s'agit de Pierre IV] inceptas, eo quod infantissam Constanciam, ipsius regis filiam, pro primogenita iurare nequiverant, maximo labore atque industria destruxit et conscios coniuracionis huiusmodi pena capitis condemnavit $»^{76}$. Tomich se tait, même lorsque, au

Aragon : para ser como tercero entre los del reyno y su rey»

72 Ibid., fol. $3 \mathrm{r}^{\circ}$ : «y por esso este regimiento de Aragon es el mas real mas noble y mejor que todos los otros. y el rey que assi rige : es rey mas entero que todos los otros. porque es mas conforme libre y mejor : y mas allegado a virtud razon justiçia y policia que los otros : porque ni el rey sin el reyno : ni el reyno sin el rey pueden propiamente fazer abto de corte : ni alterar lo assentado vna vez. mas todos juntamente han de concurrir en fazer de nueuo leyes»; et dans le récit du même règne, fol. 7 : «mas aca en Aragon como antes deximos el fazer delas leyes al rey y reyno solamente pertenece. que no pueden tan de ligero errar como vno ni dos : y el oficial que llaman justicia no digo que puede fazer leyes. mas ni juzgar puede : ni exercir juredicion saluo segund las leyes por el rey y reyno ordenadas. que llamamos comunmente fueros [...] por que assi pues [la libertad : el mando : la justicia : ley pro comun : publico poder : autoridad : derecho : y juridicion] queda enel rey y enlos quatro braços del reyno que son la cabeça y miembros mas nobles que todos los otros. queda mejor : pues queda en la comunidad, que mas de razon mirara en lo que cumple al procomun y publico beneficio que el particular miraria [...] y assi en Aragon tenemos remedio para templar y medir la saña del principe [...] y para dar y quitar poder a quien dar y quitar se deue»

73 Coronica, fol. $89 v^{\circ}-139 r^{\circ}$.

74 José María LACARRA, Aragón en el pasado, Madrid : Espasa-Calpe, 1977 (1ère éd., 1972), p.97.

${ }^{75}$ De genealogia, fol. $4 \mathrm{v}^{\circ}-5 \mathrm{r}^{\circ}$.

76 Cronica, p. 90. 
cours du règne de Pierre IV, il évoque le châtiment des chefs unionistes : «Mais pendant ce temps, le roi Pierre fit mourir ses frères, le comte d'Urgel et l'infant Ferdinand, et de même il fit mourir son autre frère appelé Jean au moyen de certaines lettres qu'il fit au roi de Castille qui lui donnaient à entendre que sa soeur, mère du dit infant, devait tuer son frère le roi de Castille et faire son fils roi. Et pour cette raison, le roi de Castille tua la soeur et le neveu.»77 Il semble bien que Sículo fasse déjà allusion au mouvement unioniste lorsqu'il évoque, dans son récit du règne d'Alphonse III, les hommes «scandaleux et séditieux» auxquels fut confronté le roi d'Aragon ${ }^{78}$. Il ne s'émeut guère, non plus, du sort réservé par Pierre IV à l'infant Ferdinand et à ses partisans : «Il tua son frère Ferdinand, lequel avait agité contre lui et poussé à la rébellion bien des gens du royaume d'Aragon. Il fit de même couper la tête, à Saragosse, à quelques nobles qui avaient suivi le parti du dit Ferdinand ${{ }^{79}}^{79}$. Il montre enfin, dans une mise en scène vigoureuse, l'abrogation par Pierre IV des concessions consenties par ses prédécesseurs : «Sur ce même lieu, il trancha et déchira le Privilège de l'Union avec son poignard. La colère avec laquelle il le trancha fut telle que, dans sa précipitation, il se blessa la main gauche $»^{80}$. L'institution du Justice, très enracinée et plusieurs fois soutenue et améliorée par la royauté ${ }^{\prime 1}$, pouvait, sans faire violence à la couronne, passer dans le discours historique pour une caractéristique juridictionnelle de consensus. Mais l'on conçoit aisément que Sículo, dont l'oeuvre concorde pourtant si souvent avec notre texte, et d'autres historiens -pensons à Tomich, lui-même si proche, à l'occasion, de celui-cisoient éloignés du Generatio sur les sujets épineux que constituaient l'Union de même que les Fors d'Aragon, dont la défense fut toujours mise en avant par les unionistes. Quant à Vagad, qui avait été chroniqueur royal ${ }^{82}$, certes, mais qui écrivait désormais sa chronique à la demande des députés du royaume d'Aragon ${ }^{83}$ et dont les sympathies avec plusieurs hauts représentants de la noblesse aragonaise, notamment la maison de Bolea, sont bien connues ${ }^{84}$, il se prononce, au nom des «libertés» aragonaises, en faveur des unionistes et jette le blâme sur Pierre IV, leur bourreau. Mais, forgeant en faveur des

\footnotetext{
77 «Empero durant aquest temps lo Rey en Pere feu morir sos frares lo Comte en Jaume de Urgell : el Infant don Ferrando e axi matex feu morir laltre frare seu appellat Johan ab çertas letras que feu al Rey de Castella donant li entendre que sa sor mare del dit Infant deuia matar a son frare lo Rey de Castella e fer son fill Rey : e per aquesta raho lo rey de Castella mata la sor e lo nebot» (Histories, fol. $47 \mathrm{r}^{\circ} \mathrm{a}$ ). B. Sánchez Alonso indique cependant que les premières impressions «abrègent beaucoup»le récit de Tomich (Historia de la historiografía, 1947, p. 332).

${ }^{78}$ Cronica d'Aragon, fol. $44 v^{\circ}$.

${ }^{79}$ Ibid., fol. $49 \mathrm{r}^{\circ}$.

${ }^{80}$ Ibid., fol. $49 \mathrm{r}^{\circ}$.

${ }^{81}$ J. M. LACARRA, Aragón... : Jacques Ier (p. 95-96), Pierre III (p. 93), Pierre IV (p. 104).

${ }^{82}$ Vid. infra note 145 et passage correspondant.

${ }^{83}$ Coronica, fol. A1 $v^{\circ}$ : «por mandado y ruego delos señores diputados del reyno de Aragon».

84 TATE, Ensayos..., p.263-279 (délicieuse lecture!). La Coronica de Aragon comporte, dans sa partie finale, une liste des personnes ayant soutenu l'entreprise de l'auteur (fol. $\left.106 \mathrm{r}^{\circ}\right)$. Parmi elles figurent Louis de Hijar, comte de Belchite, Philippe de Castro, vicomte d'Illa, et Ferrand de Bolea. L'amitié de Vagad avec ce dernier personnage et sa famille était ancienne et profonde.
} 
idéaux unionistes un véritable plaidoyer d'historien, sans doute s'interdisait-il conséquemment d'attribuer à l'Union quelque lointaine origine légendaire.

Dans le cadre d'un jeu d'échos qui demeure, notre sommaire entretient donc avec l'historiographie espagnole orientale des $\mathrm{XV}^{\mathrm{e}}$ et XVIe siècles, quant à la légende d'Iñigo Arista, un rapport singulier. C'est que cette légende agençait trois thèmes qui, mis ensemble, devenaient emblématiques de la résistance du «royaume» au pouvoir royal. Proclamation «unioniste»? Reflet de nostalgies liées au moment qui marqua le faîte de la puissance nobiliaire face à la couronne? Revendication traditionaliste d'élites confrontées à la concurrence de puissances sociales ou politiques voisines, catalanes, navarraises ou même castillanes? Quels que soient la date et le contexte de sa composition, c'est certainement de la noblesse aragonaise ou du moins d'un parti qui compte sur ou avec l'appui de celle-ci qu'émane le sommaire historique de notre Generatio regum Aragonum ${ }^{85}$. Qu'en est-il, maintenant, de son encadrement?

Notes marginales. Quelque interprétation qu'il faille finalement donner aux faveurs faites aux Aragonais par le sommaire historique, nous avons vu que celles-ci sont encore amplifiées par les notes qui l'accompagnent. Si le premier attribue l'élection royale de Garsias Jimenez aux «chrétiens» réfugiés dans la province d'Aragon, les secondes -allant au delà de tous les textes dont nous avons relevé les affinités avec le sommaire ${ }^{86}$ - voient d'emblée dans cet événement l'institution d'un «rex Aragonum», et si le sommaire dit de Ramire Ier qu'il fut «le premier à être appelé (vocatus fuit) roi d'Aragon», le commentaire, logiquement, nuance : «Premier à s'intituler (qui se intitulavit)». En marge du paragraphe que le sommaire historique consacre à Sanche le Grand, le commentateur inscrit : «Hic fuit imperator Ispanie et per uxorem rex Castelle». Ce propos s'écarte de la tradition historiographique léonaise et castillane aussi bien que des premières expressions d'une historiographie navarro-aragonaise (Généalogies de Roda, Liber regum). Celles-ci n'attribuaient à Sanche le Grand ni le titre de «roi de Castille»-sa femme étant comtesse- ni celui d'«empereur d'Espagne» réservé traditionnellement aux rois de León ${ }^{87}$. Il diffère même un peu de CSJP, qui, tirant déjà les dignités vers la couronne aragonaise, se contentait cependant d'indiquer

\footnotetext{
${ }^{85}$ Entre CSJP et la Genealogia, nous n'avons pointé que les écarts utiles à notre propos. D'autres différences sont observables, dont certaines ne relèvent sans doute que d'erreurs de transcription. Comme toute l'historiographie catalane et aragonaise du $\mathrm{XV}^{\mathrm{e}}$ siècle, la Genealogia écourte la première dynastie royale à hauteur de Sanche Garsès alors que CSJP et Domenech la conduisaient jusqu'au fils et au petitfils de celui-ci, Jimeno Garsès et Garsias -sans dire grand chose, il est vrai, de ces deux hommes. Paradoxalement, les Sarrasins sont censés être entrés en Espagne «par le royaume de Grenade»; mystérieusement, ils l'occupent jusqu'en 1002, date qui ne correspond à aucun événement décisif de la «reconquête» (sinon à la mort d'Almanzor à Medinacli?). Le vainqueur de Sanche Garsès, Almanzor «de

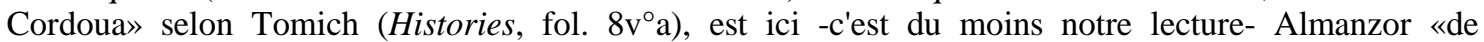
Cardona». La localisation de l'élection d'Iñigo Arista («apud Jucar») rappelle («circa ciuitatem Iacce») celle du mont Oroel où, selon $C S J P$ et sa tradition, se réfugient les trois cents chrétiens qui réchappent à la défaite de Rodéric. Enfin, la Genealogia est, à notre connaissance, le seul texte qui compte la Castille parmi les territoires dominés par Garsias Iñiguez, fils d'Iñigo Arista.

${ }^{86}$ Vid supra passages correspondant aux notes 16 à 37.
} 
«ex causa sue uxoris fuit dominatus in Castella [et in Legione usque ad Portugaliam]» et, concernant le titre impérial, «propter latitudinem terrarum quas possidebat et quibus dominabatur, fecit se nominari Imperatorem ${{ }^{88}}^{8}$, propos que reprenait du reste au mot près Jacques Domenech ${ }^{89}$. À son tour, cette note marginale s'apparente plus nettement à l'historiographie orientale des XVe et XVIe siècles. «Emperador de Hispanya» est la formule employée par Pierre Tomich, bien que, sur la question de la royauté castillane, celui-ci -qui, d'ailleurs, tient que le Navarrais avait épousé «la fille du roi de Castille»se limite à déclarer que Sanche «avait seigneurie» sur le royaume castillan ${ }^{90}$. Notre système est complet dès la Chronique des rois de Navarre, où Charles de Viana écrit : «[Sanche le Grand] régna en Castille par son mariage avec doña Mayor, fille et héritière du comte Sanche de Castille» et «Sanche le Grand, empereur d'Espagne...»»1. Évoquant la titulature adoptée par Sanche à la suite de son mariage, Vagad déclare quant à lui : «il s'intitula non plus comte de Castille, comme le faisaient auparavant les seigneurs de

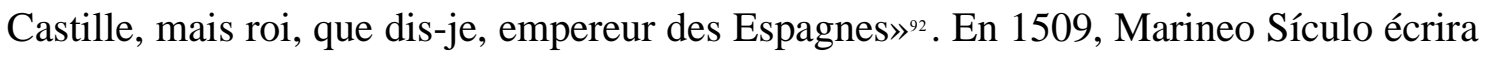

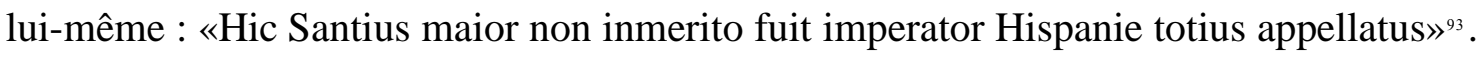
La généalogie dynastique partage avec les notes cet aragonisme renforcé.

Généalogie dynastique. Dans celle-ci, l'autorité des premiers dynastes, d'Iñigo Arista à Sanche le Grand, ne reçoit aucune qualification territoriale. Ceci permet de masquer -aussi complètement, souvenons-nous, que le fait Sículo- le caractère primordial traditionnellement conféré à la Navarre qui marque encore le sommaire. Titulatures et qualifications territoriales n'interviennent ici qu'à partir de la progéniture de Sanche le Grand, l'Aragon et son roi Ramire occupant alors (colonne de gauche) la place d'honneur dans le tableau : «Ranimirus in Aragonia rex ex prima uxore». Observons l'absence d'ordination. Ramire n'est pas qualifié de «primus rex», comme s'il prolongeait un tronc déjà aragonais. De même, nous avons vu la généalogie -conforme

\footnotetext{
${ }^{87}$ MARTIN, Les juges..., p. 30, 35, 138-139. Seul Luc de Tuy voyait cependant Sanche «régner en Navarre et en Castille» après la mort de l'infant Garsias (ibid., p. 241, n. 74). Alphonse VII était l'«Empereur» par antonomase dans la tradition navarro-aragonaise fondée par le Liber regum.

${ }^{88}$ UBIETO, p. 44. Mêlant les situations politico-matrimoniales de Sanche le Grand de Navarre et de Ferdinand Ier de Castille, CSJP introduisait ainsi dans l'historiographie de l'Espagne orientale l'erreur promise à une grande fortune que Sanche aurait dominé le León par sa femme.

${ }^{89}$ Cronica, p. 66 : «Racione autem uxoris sue, tenebat Castellam et regnum Legionis usque Portugaliam», «Et propter inmensitatem terrarum quas possidebat fecit se intitulari imperatorem».

${ }^{90}$ Histories, fol. $9 \mathrm{r}^{\circ} \mathrm{b}$ : «Apres dela mort del Sanxo Garçia dessus dit fou Rey son fill appellat Sanxo lo maior : e pres per muller la filla del rey de Castella appellada per son nom dona Maior : per que aquell rey don Sanxo fou gran Rey en Hispanya : car ell senyorejaua los regnes de Leon e de Castella per la Reyna sa muller : e assi matex Nauarra e Arago e Subarbia e Ribagorça de que lo Rey don Sanxo fou appellat Emperador de Hispanya.»

${ }^{91}$ Crónica de los reyes, p. 55 : «[...] e regnó en Castilla mediante el casamiento suyo con Doña Mayor du muger, e fija e heredera del conde D. Sancho de Castilla; el qual rey D. Sacho el Mayor, emperador de España...».

92 Coronica, fol. $21 \mathrm{v}^{\circ}: \ll[\ldots]$ mas llamose no ya conde como antes se dezian los señores de castilla : mas rey. que digo rey. mas emperador delas Españas».

${ }^{93}$ De genealogia, fol. $6 \mathrm{r}^{\circ}$.
} 
sur ce point à $C S J P^{94}$ et à sa tradition- compléter le sommaire historique en rappelant, à propos de la mort sans postérité de Gonzague de Sobrarbe, que ses vassaux se placèrent aussitôt sous la seigneurie de Ramire Ier d'Aragon. Enfin, l'auteur minore par deux fois, dans le mariage de Pétronille d'Aragon avec Raymond Bérenger IV de Barcelone, les conséquences d'une union qui pouvait être perçue comme favorable aux Catalans. En contradiction avec la coutume successorale du royaume d'Aragon ${ }^{95}$ ainsi qu'avec une grande partie de la tradition historiographique (quoique en conformité avec Domenech et Tomich) ${ }^{\circ}$, il montre Pétronille succédant à son père Ramire le Moine -«Ranimirus/Patronilla uxor Raymundi Berengarii comitis Barchinone»- et suggère que la souveraineté s'est transmise à l'épouse et non à son mari. D'autre part, quand toute la tradition historiographique catalane et aragonaise jusqu'à Sículo (hormis Vagad, cependant) donnait au fruit de cette union, Alphonse II, le titre de «roi d'Aragon et comte de Barcelone» ${ }^{97}$, notre auteur marque seulement en lui la continuité de la royauté aragonaise : «Adefonsus filius primus rex Aragonum post unionem».

Ainsi, le Generatio regum Aragonum apparaît comme une variante vivement pro-aragonaise de l'histoire des rois d'Aragon. Son sommaire historique est bâti sur le modèle de la Chronique de Saint-Jean de la Peña mais il s'apparente à l'historiographie

94 UBIETO, p. 49-50, etc.

95 Sur l'exclusion des femmes de la succession à la royauté aragonaise et les débats qu'elle suscite au XVe siècle, TATE, Ensayos..., p. 223 et 277-278.

96 Avant CSJP : MARTIN, Les juges..., p. 178-179. CSJP : «Et [...] regnum Aragonum deficiente in eo herede masculo, per contractum matrimonii, peruenit ad comitem Barchinone» (UBIETO, p. 100) et de façon plus complète : «Iste nobilissimus uir duxit in uxorem filiam Remiri, regis Aragonum, uocatam Patronillam, que postea fuit uocata Urraca, pro cuius dote habuit regnum Aragonum... Iste intitulabat se principem Aragonum et comitem Barchinone. Aragonenses enim noluerunt quod se intitularet regem Aragonum, quod tamen Alfonsus, filius eius, fecit» (ibid., p. 122). Sur ce point, Domenech ne suit pas sa source : «Et defecit linea regnum Aragonie masculina et devolutum est regnum ad mulierem Urracam vel Peyronetam appellatam. Ista domina regnavit in regno Aragonie a divisione regni Navarre citra in sexto loco, et contraxit cum nobili viro comite Barchinone, Raimundi Berengarii, huius nominis quartus... [Raimundus Berengarii] contraxit autem matrimonium cum domina Urraca, adhuc puella, regina Aragonie. Numquam tamen voluit rex appellari, sed administrator regni, nec arma comitatus mutare, unde adhuc signa regalia sunt illa que comitis Barchinone erant» (Cronica, p. 76-77). Tomich, qui donne un grand développement aux démarches conduisant à l'union, reste proche de Domenech : «E apres mort del dit rey [Ramiro] los Aragonesos donaren marit ala Reyna la filla lo illustre Princep e egregi Comte de Barçelona en Ramon Berenguer...» (Histories, fol. 10v a), puis le long récit des fol. 29v $\mathrm{v}^{\circ}-30 \mathrm{r}^{\circ}$. Vagad, favorable à la «loi salique», voit régner le comte : «Reinó después don Ramón/ que llamaron Belenguer./ Fue la causa y la razón/ Petronilla y su muger,/ hija del Rey de Aragón.// Por valor de su persona/ don Ramiro los casó/ al Conde de Barcelona/ con su hija y la corona/ de sus reinos le entregó» (Épilogue, $\S$ 85-86; TATE, p. 320 et justification politique p. 278); Sículo fait de même, revenant plus strictement à la version de CSJP : «A cause de cela, Ramire dut accepter le royaume, et il se maria avec la fille du comte de Poitiers, de laquelle il eut une fille appelée Pétronille qui fut ensuite mariée à Raymond Bérenger, comte de Barcelone et lui donna en dote le royaume d'Aragon» (Cronica d'Aragon, fol. 12 $\mathrm{v}^{\circ}$ ), et aussi : «Raymond Bérenger, comte de Barcelone (comme nous l'avons dit plus haut) succéda dans le royaume d'Aragon au roi Ramire son gendre pour la raison de s'être marié avec Pétronille sa fille» (ibid., fol. 14r ${ }^{\circ}$ ). Sur l'image qu'avait Raymond Bérenger de son pouvoir, LACARRA, Aragón en el pasado, p. 75 (bibliographie p. 222).

97 CSJP : UBIETO, p. 99 et 125; Domenech : Cronica, p. 78; Tomich : Histories, fol. 30vºb; Sículo : Cronica d'Aragon, fol. 26r ${ }^{\circ}$. Vagad, du moins dans son Épilogue, ne tient aucun compte de la composante catalane lorsqu'il continue de filer, au delà, de Raymond Bérenger IV, les successions royales aragonaises : «El reino luego se ofreçe/ al Rey don Alfonso el Casto...» ( $\$ 87$ sq.; TATE, p. 320). 
catalane et aragonaise du XVe siècle par ses innovations favorables à la couronne d'Aragon et, plus encore aux oeuvres qui exaltent le royaume d'Aragon stricto sensu. Cet aragonisme épouse ici le parti d'une noblesse acquise à la cause ou attachée au souvenir de l'Union. Les commentaires portés en marge du sommaire, de même que la généalogie dynastique, tous deux liés aux mêmes courants de l'historiographie, accentuent encore la primauté aragonaise aux dépens des autres entités territoriales d'Espagne et notamment de celles le plus étroitement associées à l'histoire de l'Aragon : la Navarre et la Catalogne. On ne peut aller plus loin sans tenter de dater l'oeuvre et d'indentifier son auteur.

\section{Datation, auteur.}

Sommaire historique. Notre sommaire est très certainement postérieur à la Chronique de Saint-Jean de la Peña (1372) à laquelle le lient son contenu général et son organisation. Il ne lui a pas servi de source : la chronique aragonaise, composée à l'initiative de Pierre IV, n'aurait pas manqué, dans ce cas, d'y recueillir certaines données bien intéressantes, comme l'ascendance gothique de Garsias Jimenez ou la filiation légitime de Ramire Ier. Ces thèmes, comme celui des fondations institutionnelles du royaume d'Aragon, rapprochent très clairement notre Generatio d'une tradition historiographique née, certes, de CSJP, mais qui fleurit seulement dans le courant du XVe siècle, et même, semble-t-il, de sa seconde moitié. Il y a là un «environnement» textuel et idéologique auquel notre texte n'est certainement pas étranger.

À l'autre extrémité de la chronologie des oeuvres que nous avons sollicitées, notre texte entretient avec le De genealogia regum Aragonum que Lucio Marineo Sículo (1509) trois coïncidences exclusives : l'origine gothique non royale de Garsias Jimenez, les conditions imposées à Iñigo Arista lors de son élection à la royauté, l'imputation de la mort de Garsias de Navarre à son neveu Sanche Ramirez. Il en est d'autres qui jusqu'ici n'intéressaient pas notre propos. Comme notre Generatio, l'oeuvre de Sículo date l'entrée des Sarrasins en Espagne de la première moitié du VII ${ }^{\mathrm{e}}$ siècle -de 617 , toutefois ${ }^{98}$-, l'élection de Garsias Jimenez de $708^{99}$, sa mort de $758^{100}$, la mort de Fortuné Garsias de $815^{101}$. Sículo -deux autres singularités du sommaire relativement à CSJP et à sa tradition- donne au traître Julien le titre de «comte de Cantabrie» ${ }^{102}$ et estime à 600 hommes, au lieu de 300 , les premières forces des réfugiés chrétiens ${ }^{103}$. Si

${ }^{98}$ De genealogia..., fol. $3 \mathrm{v}^{\circ}$. Sur ces datations et leur différence relativement à CSJP, voir passage correspondant à la note 14 .

${ }^{99}$ Ibid., fol. $3 \mathrm{v}^{\circ}$.

$100 \mathrm{Ibid}$., fol. $4 \mathrm{r}^{\circ}$. Vagad donne cependant la même date (Coronica, fol.10r $\left.{ }^{\circ}\right)$.

${ }^{101}$ Ibid., fol. $4 v^{\circ}$. CSJP et alii : non datée. Vagad, selon ses sources, propose deux dates : 815 ou 822 (Coronica, fol. $\left.14 \mathrm{r}^{\circ}\right)$.

102 Ibid., fol. $3 \mathrm{v}^{\circ}$.

${ }^{103} \mathrm{Ibid}$., fol. $4 \mathrm{r}^{\circ}$. CSJP : UBIETO, p. 25. CSJP, toutefois, chiffrait à six cents hommes la seconde vague des chrétiens réfugiés à Saint-Jean de la Peña après l'offensive victorieuse d'Abd al-Rahman contre le roi 
l'on ajoute à cela les nombreuses innovations dont nous avons vu que l'oeuvre de Sículo et le Generatio les partagent communément avec telle ou telle autre chronique (élection de Garsias Jimenez à Saint-Jean de la Peña, abréviation de la dynastie comtale aragonaise au niveau de Galindo et de la première dynastie royale à hauteur de Sanche Garsès ${ }^{104}$, élection d'Iñigo Arista par «les Navarrais et les Aragonais», naissance légitime de Ramire Ier), il est difficile de nier que les deux textes soient liés par quelque dépendance.

Notre sommaire historique ne constitue pas un résumé de l'oeuvre de Sículo et il est même très improbable qu'il s'en inspire. Dans la tradition de CSJP, il donne en effet volontiers aux rois fondateurs le titre de «rex Navarre» alors que Sículo, laissant délibérément dans le flou les territoires sur lesquels ils régnèrent ${ }^{105}$, évite toute mention d'une dynastie royale navarraise antérieure à l'existence des rois d'Aragon. Dans notre sommaire historique, comme dans CSJP et sa tradition ${ }^{106}$, le dernier fils de Sanche le Grand est appelé Gonzague, et il reçoit en héritage le Sobrarbe. L'opinion de Sículo est que ce fils se nomma non pas Gonzague mais Sanche; et il préfère appeler son héritage «Vasconie $»^{107}:$ :De [Eluira] tres illi filii nati fuere : Garsias : Ferdinandus : et Santius», «Tum demum omnium consensu ab imperatore cum vxore statutum est : vt Garsias in Nauarre : Ferdinandus Castelle : Santius : quem nonnulli Gonsaluum nominarunt : in Vasconie et Ramirus in Aragonie regno succederet», «Hispanie regnorum partitionem supra demostrauimus : quemadmodum scilicet Garsie Nauarra : Ferdinando Castella : Santio Vasconia : quam Suprarbrum alii vocant et Ramiro Aragonia contigit» ${ }^{108}$. Sanche est, au demeurant, le nom sous lequel ce personnage apparaît ensuite dans le récit de Sículo $^{109}$. Sur ces deux points, notre sommaire historique ne s'inspire donc pas du De

Ordoño de León et le recul consécutif de l'ensemble des positions chrétiennes (ibid, p.29-30). Mais cette donnée ne fut pas reprise par l'historiographie.

104 Cf. note 85 .

105 Cf. note 37.

106 CSJP : UBIETO, p. 44 et 47; Domenech : Cronica, p. 66; Tomich : Histories, fol. 9v ${ }^{\circ}$; Vagad : Coronica, fol. $20 \mathrm{v}^{\circ}$ et $28 \mathrm{r}^{\circ}$.

${ }^{107}$ La source de Sículo est-elle, sur ce point, une première rédaction de la Chronique attribuée à Pierre de Valence? Peu après 1410, le premier rédacteur de l'oeuvre écrit en effet : «Este rey y emperador don Sancho tubo de su muger, la reyna doña Elvira, tres hijos varones : el mayor se llamó don García; el segundo don Fernando el Magno (este fue rey de Castilla y de León); el tercero se llamó don Sancho», et plus loin : «Puso también en posesión a su hijo don Sancho -otros le llaman don Gonzalo-, en el condado de Ribagorza, y en las otras tierras, conviene a saber : Sobrarve et Loarre et Samedel». C'est la seule correspondance que nous connaissions avec la nomination de Sículo. En revanche, la chronique de Pierre de Valence suit la tradition dominante quant à la désignation de la seigneurie de Sanche (également : «Este infante, reinando en Sobrarbe y Ribagorza...») [Agustín UBIETO ARTETA, éd., PEDRO de VALENCIA, Crónica, Saragosse : Anubar (Textos medievales, 84), 1991, p.35 et 50]. La genèse de cette oeuvre, dont le noyau primordial fut, selon l'expression de son éditeur, «repris et adapté» dans la seconde moitié du XVIe siècle, pose encore trop de problèmes pour que nous puissions tirer quelque leçon fiable de sa comparaison avec le De genealogia de Sículo ou tout autre texte de notre corpus.

${ }^{108}$ De genealogia..., fol. $6 \mathrm{r}^{\circ}-6 \mathrm{v}^{\circ}$.

${ }^{109} \mathrm{Ibid}$., fol. $7 \mathrm{r}^{\circ}:$ «Ramiri tempore Santium frater eius Suprarbrorum rex occisus est a quodam vascone nomine Tomanerio...» 
genealogia. Sur le premier d'entre eux il est contraire au système mis en place par Sículo. D'autres indices, d'ordre lexical ou stylistique pourraient être allégués dans le même sens. Notre sommaire, par exemple, use d'une titulature des rois d'Aragon attestée par l'usage diplomatique («rex Aragonum») plus traditionnelle et ancienne que celle constamment adoptée par Sículo («rex Aragonie») ${ }^{110}$. D'une façon plus générale, la forme même de notre texte, naturelle et sans fard, ne reprend rien de l'humanisme stylistique du Sicilien.

A l'inverse, certains comportements du De genealogia pourraient conduire à penser que son auteur comptait notre texte (ou éventuellement celui dont sans doute il dérive) parmi ses sources. C'est notamment le cas lorsque le récit de Sículo juxtapose ou alterne, plus qu'il ne marie, deux versions des faits dont l'une consitue une caractéristique absolument distinctive ${ }^{111}$ du sommaire historique du Generatio.

Notre sommaire attribue la mort de Garsias de Navarre, fils de Sanche le Grand, à Sanche Ramirez d'Aragon. Sículo, nous l'avons observé, fait d'abord de même : «Deinde bellum quoque gessit cum Garsia patruo rege Nauarre : quem vicit et occidit»112 ; mais, dressant ensuite la généalogie de Garsias Ramirez, il écrit, plus orthodoxe : «Erat autem Garsias Ramirus filius Garsie regis Nauarre : quem Ferdinandus rex Castelle frater eius occiderat $»^{113}$. Concurrence de sources. Dans l'état de nos connaissances, la Genealogia est le seul texte qui partage avec Sículo la première version des faits.

Prenons maintenant le cas d'Iñigo Arista. Concernant son élection, Sículo écrit d'abord -dans le sillage de Vagad?- : «Et Aragones Ennicum cui Arista cognomen erat [...] sibi regem delegerunt». Il affirme ensuite : «princeps a Nauarris et Aragonibus eligitur ${ }^{14}$. Ces derniers mots sont moins proches de ceux de Tomich $(«[\ldots]$ los Nauarresos e Aragonesos... elegiren per lur rey vn caualler de Bigorra lo qual era appellat per son nom Eniego...» ou de ceux Rodrigue de Tolède, dont Tomich se réclame («inter incolas regni meruit principatum») $)^{115}$, que de notre texte : «Et

$110 \mathrm{Ibid}$., fol. $3 \mathrm{v}^{\circ}(\ll$ Ramirus ex gothica gente procreatus primus Aragonie regni titulis et honoribus insignitus perhibetur»; fol. $4 \mathrm{r}^{\circ}$ («De Garsia Ximenio Suprarbrorum rege. Cui non Aragonie : sed Pyreneorum montium et Suprarbrorum regis nomen posuerunt»); fol. $6 \mathrm{v}^{\circ}$ ( De Ramiro Aragonie rege primo»); fol. $7 \mathrm{r}^{\circ}$ («Ramirus igitur mortuo patre regis Aragonie nomen [...] accepit», etc. «Rex Aragonum», «regnum Aragonum»sont les formulations que l'on trouve dans CSJP. Domenech, en revanche, use dès 1380 de la titulature «rex Aragonie» (LóPEZ ELUM, p. 71, 74, 85) en alternance avec «rex Aragonum» (ibid., p. 72, 74, 85). «Rex Aragonum» est la titulature habituelle dans la documentation, cf. Ambrosio HUICI MIRANDA et María Desamparados CABANES PECOURT, Documentos de Jaime I de Aragón, 5 t., Valence : Anubar (Textos medievales, 49-51, 55, 77), 1976-1988; M. D. CABANES PECOURT et Luisa CABANES CATALÁ, Rex Aragonum aureum opus de Xativa, Saragosse : Anubar (Textos medievales, 88), 1996; María José FREIRE MOLINER, El libro registro de los privilegios de la Albufera de Valencia, Saragosse : Anubar (Textos medievales, 90), 1995 (dans ces recueils : chartes de Jacques I, Jacques II, Alphonse III, Pierre IV, Jean Ier, Martin Ier, Ferdinand Ier et Jean II).

111 Voir cependant les réserves que nous formulons en note 9.

$112 \mathrm{Cf}$. note 55 et passage correspondant.

${ }^{113}$ De genealogia, fol. $9 \mathrm{r}^{\circ}$.

$114 \mathrm{Cf}$. note 48 et passage correspondant.

115 Cf. note 43. 
Navarrenses atque Aragonenses apud Jucar se in eorum principem eligerunt». Or, tandis que Sículo marque quelques réserves quant à l'origine que prêtent à Iñigo $C S J P^{116}$ et sa tradition -«Ennicum cui Arista cognomen erat : ex gothica gente : vel ut alii volunt ex comitatu Bigore : sibi regem delegerunt»-, l'auteur de notre sommaire reste quant à lui conforme à $C S J P$ et ignore l'origine gothique d'Iñigo. L'analogie textuelle concernant l'élection d'Iñigo Arista tient donc à une dépendance du texte de Sículo relativement au sommaire historique du Generatio (ou à son modèle) et non à une dépendance inverse. On s'expliquerait d'ailleurs mal que, s'inspirant de Sículo et écrivant après 1509, l'auteur de notre texte ait créé la légende -absente de sa source ${ }^{117}$ - d'un Iñigo Arista fondateur d'une Union dont l'enjeu politique, à cette époque tardive, avait perdu toute actualité. Nous serions bien plutôt tentés de croire, à l'inverse, que c'est Sículo, dont la sympathie, nous l'avons vu, ne va pas aux unionistes ${ }^{118}$, qui, supprimant toute référence à l'Union et réduisant les Fors à «une loi équitable», tronque et édulcore le propos de notre sommaire.

Les faits d'expression, du reste, vont dans le même sens. Prenons l'accord de Vadoluengo. CSJP résumait la clause fondamentale en ces termes : «[...] conuenerunt in certis capitulis [...] quod rex Remirus [...] toti dominaretur populo et rex Garsias omnibus militibus... $\gg^{119}$ Domenech ne rapporte pas le contenu du pacte ${ }^{120}$; Tomich n'évoque même pas l'épisode ${ }^{121}$. Charles de Viana suit en tout point CSJP, dont il traduit ainsi le texte : «[...] ficieron ciertos capitulos; es a saber, que el rey D. Ramiro [...] fuese sobre todo el pueblo, e el rey D. Garcia sobre todos los cabailleros.... ${ }^{122}$ Notre sommaire retient la leçon traditionnelle quant au pouvoir de Ramire : «fuit rex Aragonum et in Navarra super totum populum». En revanche, il utilise un désignatif sociologique supplémentaire pour définir le pouvoir de Garsias Ramirez qui, désormais, s'exerce «super milites et infancones». Vagad traduit-il (à sa façon, différente de celle du prince de Viana) le «milites» de CSJP ou bien synthétise-t-il la terminologie duelle de notre sommaire ${ }^{123}$, lorsqu'il écrit : «[...] assentaron la concordia desta manera : que el rey don remiro fuesse recebido por señor delos pueblos y asi le recibieron : y el rey don garci

\footnotetext{
116 UBIETO, p. 32 : «quidam uir oriundus comitatus de Bigorra, vocatus Ennecus».

117 Vid. supra passage correspondant à la note 75 .

118 Vid. supra passage correspondant aux notes 78 à 80.

119 UBIETO, p. 90.

120 Cronica, p. 76 : «Et, se interponentibus probis viris, concordatum est, et quia gerram verterent contra serracenos». Â cela se borne l'évocation de Domenech, qui reprend, en l'abrégeant, la fin du propos de CSJP : «[... omnibus militibus], quoque rancorem et odium quos hostis humani generis procurauerat et posuerat inter eos ac eorum subditos, conuerterent contra sarracenos».

121 Histories, fol. $10 \mathrm{r}^{\circ} \mathrm{a}:$ «[...] mas los Nauarresos no volgueren lo dit Ramiro per Rey : e per aquesta raho foren separats los regnes la vn del altre daqui auant»

122 Crónica de los reyes, p. 93.

123 Bien entendu, ceci plaiderait en faveur de l'antériorité du sommaire relativement à la Chronique de Vagad, hypothèse que nous défendons dans les paragraphes suivants.
} 
remirez mandasse los fidalgos» ${ }^{124}$ ? Sículo écrit quant à lui : «[...] sententiam protulerunt. Ut Ramirus rex Aragonum : Nauarrae populis omnibus imperaret : et Garsias magister equitum diceretur et ius in nobiles haberet» ${ }^{125}$. Que le rapport de dépendance entre notre texte et le De genealogia soit direct ou indirect, il est clair que le lexique employé par Sículo relève d'une latinisation -milites>equites, infançones>nobiles- de l'usage naturel, ancré dans la tradition, dont témoigne le sommaire. Le De genealogia est donc second par rapport à celui-ci ou au système que celui-ci représente.

Ainsi, notre sommaire historique ou le texte qu'il résume est postérieur à la Chronique de Saint-Jean de la Peña (1372) et antérieur au De genealogia de Lucio Marineo Sículo (1509). La fourchette est large, pouvons-nous la resserrer?

Avec Pierre Tomich (1448), l'auteur de notre texte rattache Garsias Jimenez au peuple des Goths, tient que Pampelune fut conquise par son fils Garsias Iñiguez, écourte la dynastie comtale aragonaise au niveau de Galindo ${ }^{126}$ et la première dynastie royale pyrénéenne au niveau de Sanche Garsès ${ }^{127}$, rattache le comté d'Aragon à la couronne navarraise par le mariage de Fortuné Garsès avec la fille de Galindo, voit Sanche Garsès tomber sous les coups d'«Almanzor de Cordoua» ${ }^{128}$ et Iñigo Arista être élu par «Navarrais et Aragonais». Tous deux associent également la mort du roi Garsias de Navarre, fils de Sanche le Grand, à une guerre qui l'aurait opposé à Sanche Ramirez d'Aragon. Dans les limites -trop étroites, sans doute ${ }^{129}$ - de la littérature historiographique qui nous oriente, l'oeuvre de Tomich est la première qui partage ces données avec notre texte. En revanche, Tomich semble ignorer la thèse de la filiation légitime de Ramire Ier d'Aragon, que pose pourtant notre sommaire, ainsi que les fondations institutionnelles que prête celui-ci à Iñigo Arista.

Au delà de Tomich, Vagad (1499) s'accorde avec notre texte sur la naissance légitime de Ramire Ier et s'en rapproche lorsqu'il fait remonter l'institution du Justice d'Aragon, associée à un éloge des fors, aux origines de la royauté aragonaise. Avec le «cauallero tomique», dont souvent il s'autorise, Vagad partage plusieurs des informations qu'offre également notre sommaire : Garsias Jimenez est d'origine (royale) wisigothique, Garsias Iñiguez conquiert Pampelune et porte pour la première fois le titre

${ }^{124}$ Coronica, fol. $51 \mathrm{r}^{\circ}$. Le latin milites pouvait désigner le groupe nobiliaire dans son ensemble sous le rapport de la fonction de même que le roman fidalgos pouvaient le faire sous le rapport de la naissance. En association avec infançones, milites pouvait également dénoter une strate de la noblesse conçue comme un tout constitué de deux groupes hiérarchisés.

125 De genealogia, fol. $9 \mathrm{r}^{\circ}-\mathrm{v}^{\circ}$.

${ }^{126}$ Histories, fol. $8 \mathrm{v}^{\circ} \mathrm{a}$.

127 Tomich : Histories, fol. $8 \mathrm{v}^{\circ}$ a; Vagad : Coronica, fol. $15 \mathrm{r}^{\circ}$.

128 Notre manuscrit semble plutôt donner «Cardona» que «Cordoua», mais sans doute s'agit-il d'une erreur de copie. CSJP (UBIETO, p. 31) et Domenech (Cronica, p. 58) ne disent rien des circonstances de la mort de Sanche Garsès. Vagad (Coronica, fol. $15 \mathrm{r}^{\circ}$ ) et Sículo (De genealogia, fol. $4 \mathrm{v}^{\circ}$ ) le montrent mourir dans un combat contre les «Maures», sans autre précision.

129 Cf. note 9. 
de «roi de Navarre» ${ }^{130}$, la première dynastie royale s'éteint avec Sanche Garsès ${ }^{131}$. Confrontant les sources, Vagad écarte toutefois certaines de ces leçons communes (la mort de Garsias de Navarre aux mains de Sanche Ramirez, que démentait toute l'historiographie hispanique) ou se montre réticent sur leur véracité : l'extinction de la dynastie comtale aragonaise à la mort de Galindo, que contredisaient CSJP et Domenech $^{132}$; le mariage de la fille de Galindo avec Fortuné Garsès, que ni CSJP ni Domenech ne mentionnaient. D'autres données que Vagad pouvait lire dans Tomich et qui figurent aussi dans notre sommaire sont écartées pour être contraires à la représentation historique que défend le chantre de l'Aragon : il n'existe pas de rois de Navarre antérieurs aux rois aragonais; les Navarrais n'interviennent d'aucune façon dans l'élection d'Iñigo Arista. Enfin, l'on trouve dans l'oeuvre de Vagad des éléments qui sont aussi étrangers aux Histoires de Tomich qu'à notre texte : Iñigo Arista est d'origine wisigothique, de même que le comte Aznar d'Aragon; l'institution du Justice remonte, en deçà d'Iñigo, au premier fondateur Garsias Jimenez.

De ces observations, l'on peut induire une hypothèse génétique très vraisemblable. Tomich a été lu par notre auteur ou un même texte leur a servi de source (directe, pour le premier, peut-être indirecte pour le second) ${ }^{133}$. Cette source ou les Histoires, notre auteur (ou sa source directe) les additionne dans un sens favorable à l'Aragon et à sa noblesse : légitimité de Ramire Ier, fondations institutionnelles d'Iñigo Arista. Vagad, outre l'oeuvre de Tomich, connaît notre texte (ou sa source directe). A son tour, il remanie, filtrant et amplifiant. La filiation légitime de Ramire, donnée entre toutes précieuses, est retenue et exaltée. Refoulée jusqu'à Garsias Jimenez, la fondation institutionnelle des «libertés» aragonaises -hormis le Privilège de l'Union, dont Vagad tient à forger plus solidement la mémoire historique- grandit en ancienneté. Le sang wisigothique, par delà ce premier roi, parvient à tous les fondateurs : le comte Aznar, Iñigo Arista. Est écarté tout ce qui, dans l'histoire des origines des roi d'Aragon, n'est pas aragonais.

La question serait maintenant de dater l'addition des Histoires ou de leur source. Si le travail de notre auteur (ou de l'auteur de sa source immédiate) a porté sur cette source, son oeuvre (ou sa source imédiate) peut être antérieure à celle de Tomich, et celui-ci l'avoir ignorée. Nous ne serions guère avancés quant à la datation du récit historique construit ou abrégé par notre sommaire, dont les termes seraient la date de

\footnotetext{
${ }^{130}$ A propos de Garsias Jimenez, Vagad, se fondant sur «le chevalier Tomich» et «d'autres sûrs et fins chroniqueurs», déclare : «no se llamo aqueste rey rey de nauarra : mas su fijo don Garci ynigo que gano a pamplona», Coronica, fol. $8 \mathrm{r}^{\circ}$.

${ }^{131}$ Coronica, fol. $15 \mathrm{r}^{\circ}$.

132 Vagad évoque des sources selon lesquelles il y aurait eu «bien d'autres comtes en Aragon». Galindo est néanmoins le dernier comte qu'il nomme et ce qui semble être sa source principale déclare que celui-ci n'eut qu'une fille (cf. note 45).

${ }^{133} \mathrm{Ce}$ second cas de figure expliquerait que, dans le sommaire, Garsias Jimenez soit d'origine wisigothique mais non de lignage royal comme dans les Histoires de Tomich.
} 
composition de CSJP, voire de la Chronique de Domenech (qui ignore toutes ses innovations), et celle de l'achèvement de la Chronique de Vagad : pour simplifier, 13801499. L'histoire des faits ne nous apporterait ici qu'un secours bien fragile. Le moment où l'Union cessa d'exister, ou bien d'être un enjeu, ou bien même -mais comment dater la fin d'une nostalgie ou, pire encore, d'une revendication identitaire?- d'être un souvenir encore vivant, pourrait-il marquer ici un terme ad quem? Pierre IV abrogea le Privilège de l'Union à l'issue de la bataille d'Épila où, en 1348, il anéantit militairement les unionistes. L'Union cessa à jamais d'exister. Non pas, cependant, sa mémoire. L'infant Ferdinand d'Aragon (fils d'Alphonse IV et de sa seconde femme, Éléonore), qui avait été le chef de file des vaincus d'Épila, périt assassiné en Castille en 1363. Au delà, le souvenir fut sans doute porté par les descendants du fidèle lieutenant de Ferdinand, Jacques Ier d'Urgell, et notamment, au moins jusqu'au compromis de Caspe (1412), par Jacques II l'Infortuné, candidat à la royauté aragonaise et rival malheureux de Ferdinand d'Antequera. Celui-ci disparut cependant de la scène politique dès 1413, date à laquelle il se trouva emprisonné en Castille. 1380-1412 : tels pourraient être les termes d'une datation qui s'appuierait sur l'histoire vivante de l'Union. Mais en 1499 encore, nous avons vu Vagad brandir un manifeste unioniste dans le contexte, perçu comme défavorable à l'Aragon et à sa noblesse, de l'union personnelle avec la Castille...

$\mathrm{Si}$ au contraire, ne considérant que l'horizon tangible des textes en notre possession, nous tenions que l'auteur du sommaire a utilisé les Histoires de Tomich, alors c'est entre 1448 et (au plus tard) 1499 qu'il faudrait situer son travail. L'influence que semble avoir eu notre texte sur les historiens de la couronne aragonaise dans la seconde moitié du $\mathrm{XV}^{\mathrm{e}}$ siècle et les premières années du XVIe nous inciterait à pencher plutôt dans ce sens.

Le contenu historique des notes marginales et de la généalogie dynastique, quant à lui, est trop maigre pour que, sous le rapport d'une histoire des textes, nous puissions en tirer des leçons déterminantes.

Notes marginales. L'observation «Hic fuit imperator Ispanie et per uxorem rex Castelle» apparente les marginalia à l'historiographie espagnole orientale du milieu et de la seconde moitié du XVe siècle - à Tomich et, plus encore, au prince de Viana et à Vagad. C'est tout ce que l'on peut en dire. Le commentaire «Prima electio regis Argonum de Garcia Eximenez» est-il ce qui a déclenché la dénégation de Sículo («De Garsia Ximenio Suprarborum rege. Cui non Aragonie : sed Pyreneorum montium et Suprarbrorum regis nomen posuerunt»? Il en faudrait conclure que ces notes figuraient déjà en marge du sommaire historique lorsque le Sicilien, vers 1509, en prit connaissance.

Généalogie dynastique. La plupart des données que la généalogie dynastique offre en supplément du sommaire historique ne peuvent rien nous apprendre. Que 
Gonzague de Sobrarbe, fils de Sanche le Grand, fût mort sans postérité et que ses sujets se fussent placés sous l'autorité de Ramire Ier d'Aragon, ou que ce dernier eusse été tué par Sanche II de Castille, tout cela était parfaitement connu depuis la Chronique de Saint-Jean de la Peña ${ }^{134}$. Trois points ont néanmoins quelque intérêt. Notre généalogie et le De genealogia de Sículo sont les seuls textes de l'historiographie hispanique qui tiennent que Garsias (Ramirez) fut le fils du roi Garsias Sanchez de Navarre tué par Sanche Ramirez (ou Ferdinand Ier) ${ }^{135}$. À propos de Pierre III d'Aragon, la généalogie dynastique déclare : «habuit uxorem Constantiam filiam Manfredi regis Sicilie utriusque». Tomich évoquait bien cette union et ses conséquences politiques dans un discours des ambassadeurs siciliens à Pierre III : «Excellent et vertueux seigneur, les Siciliens supplient votre haute seigneurie qu'elle veuille les défendre contre leurs ennemis et vous veulent pour seigneur comme celui à qui appartient le royaume de Sicile, puisque vous avez pour femme la reine, leur seigneur, fille du roi Manfred de Sicile» ${ }^{136}$. Mais seul le De genealogia de Sículo commet avec notre généalogie l'anachronisme (vid. infra) de prêter à Manfred la titulature de «rex utriusque Siciliae»137 . Autre analogie exclusive, cette fois avec Vagad : qu'après la mort de Gonzague de Sobrarbe, «ses vassaux se donnèrent à Ramire (d'Aragon)». Dans la tradition historiographique qui nous est connue, seule la Chronique de Vagad use des termes vassaux et se donner ${ }^{138}$. Le terme du recensement généalogique étant dans notre texte antérieur à Ferdinand II (sous le règne de qui écrivent Vagad et Sículo) et l'information historique conforme par ailleurs à celle du sommaire, notamment sur des données contraires au texte de Sículo -origine d'Iñigo Arista (Bigorre), noms du frère cadet de Ramire (Gonzague) et du royaume qu'il reçoit en partage (Sobrarbe)- ou à celui de Vagad -mort de Garsias de Navarre aux mains de Sanche Ramirez-, nous serions conduits à situer la généalogie dynastique, de même que le sommaire, avant les oeuvres de Sículo et de Vagad. De leur côté, les coïncidences entre notre généalogie et les oeuvres de Vagad et de Sículo nous inciteraient en outre à considérer que généalogie dynastique et sommaire historique - de même que, dans le cas particulier du Sicilien, sommaire historique et notes marginales- étaient déjà assemblées lorsque Vagad et

134 UBIETO, respectivement, p. 49-50 et 52.

135 Cf. note 113 et citation correspondante. Une tradition issue du De rebus Hispaniae de Rodrigue Jimenez de Rada voyait Garsias Ramirez, fils de l'infant Ramire, descendre d'un frère de Sanche de Peñalén (fils de Garsias Sanchez de Navarre) lui-même nommé Sanche (CABANES PECOURT, p. 113b). L'autre tradition, fondée par CSJP, le tenait pour le petit-fils de Sanche de Peñalén.

${ }^{136}$ Histories, fol. $37 \mathrm{v}^{\circ} \mathrm{a}:$ :Excellent e virtuos senyor los sicilians supliquen a vostra gran senyoria : quels vullau defendre de lurs enemichs e volen a vos per senyor axi com aquell al qual lo regne de Sicilia se pertany qui haueu la Reyna lur senyora per muller la filla del rey Manfre de Sicilia»

137 Cronica d'Aragon, fol. $33 \mathrm{v}^{\circ}$ : «Don Pedro hijo del rey don Jaime en vida del padre \& contra su voluntad se caso con doña Costança hija de don Manfredo rey d'entramas Sicilias.»

138 Coronica, fol. 28r ${ }^{\circ}$. L'erreur «[vassalli dederunt se] Ranimiro patruo» provient sans doute d'une contamination par l'annotation précédente («Sanctius filius qui occidit Ranimirum patruum suum») que facilitait le positionnement de cette indication sur la ligne du tableau généalogique réservée aux petits-fils de Sanche le Grand. 
Sículo connurent le second. Les «petits faits» sont donc nombreux qui donneraient à penser que, dans la seconde moitié du XVe siècle, les formants textuels que nous voyons combinés sur notre manuscrit composaient déjà un ensemble.

Sur notre généalogie, cependant, c'est cette fois l'analyse historique qui nous livre la donnée la plus sûre. Le roi Manfred de Naples et de Sicile, fils naturel de Frédéric II, ne porta jamais la titulature que lui prête notre texte : «Rex Sicilie utriusque». Celle-ci fut arborée pour la première fois par Alphonse V le Magnanime, roi d'Aragon, après qu'il conquit Naples en 1443. La composante généalogique du Generatio est donc postérieure à cette date. L'indication la plus précieuse, néanmoins, devrait être la déclaration d'autorité qui paraphe le texte. Malheureusement pour nous, elle est obscurcie par la forme d'énigme que l'auteur lui a donnée.

Trois repères nous ont guidé dans le déchiffrement que, sous toutes réserves, nous en proposons. Le premier est la date de composition, certainement postérieure à 1443, de la généalogie dynastique. Le second repère est l'orientation politique vivement pro-aragonaise de l'ensemble du Generatio et de sa généalogie dynastique en particulier. Enfin, il est un indice que nous avons regardé comme une seconde énigme, une énigme qui ne se présente comme telle, mais que notre auteur aurait néanmoins conçue délibérément, comme une sorte de relais indicatif permettant, par ricochet, de résoudre l'énigme principale. La liste des rois d'Aragon que dresse la généalogie s'achève sur un roi «Joannes». Comme celui-ci vient à la suite d'un roi «Petrus» correspondant à Pierre IV le Cérémonieux, on se croirait naturellement fondé à reconnaître en ce «Joannes» le fils et successeur de Pierre, Jean Ier, qui régna en Aragon entre 1387 et 1395. Mais dans ce cas, l'on comprendrait mal pourquoi une généalogie écrite après 1443 ne mentionnerait pas les successeurs de Jean : Martin Ier, son frère, puis Ferdinand Ier d'Antequera, l'élu de Caspe, Alphonse V, fils de Ferdinand, Jean II enfin, frère d'Alphonse... La perplexité du lecteur redouble, du reste, devant ce constat : alors que tous ses ascendants portent mention de leur parenté avec leur prédecesseur («Aldefonsus filius», «Petrus filius», «Jacobus filius», «Petrus filius», «Jacobus frater», «Alfonsus filius Jacobi», «Petrus filius»), seul «Joannes»n'est pas lié parentalement à l'homme à qui il succède. Dans ce blanc, nous avons cru trouver la clé de l'énigme principale. Le «Joannes» en question pourrait ne pas être Jean Ier, mais l'auteur de la généalogie lui-même, qui, énonçant et voilant son identité dans l'énigme, pousserait assez loin le jeu pour signer dans le même temps son oeuvre de son nom : «Joannes» de Navarre, Jean II d'Aragon.

Quel homme, en effet, après 1443, a pu défendre des vues si aragonistes, qui était «duc par [sa] mère, roi par [sa] femme et marquis par [son] père», qui vainquit ou commanda -les deux sens sont possibles pour «pressi»- les Navarrais, qui, enfin, fut en 
situation de «tenir sans fausseté les droits de [son] seigneur»? Jean ${ }^{139}$ fut d'abord, à partir de 1425, roi de Navarre : par sa femme, Blanche, fille aînée et héritière de Charles III le Noble. Il le demeura après la disparition de Blanche (1441) et jusqu'à sa propre mort (1479), en dépit des revendications que son fils Charles, prince de Viana, avec l'appui d'une grande partie de la noblesse navarraise, fit valoir jusqu'en 1461, date à laquelle il décéda. Son frère Alphonse $\mathrm{V}$ tout entier occupé aux manoeuvres italiennes qui le conduiraient à la prise de Naples (1443), puis installé définitivement en Italie, Jean (au nom d'Alphonse, son frère et son seigneur) se trouva en charge, dès 1436, de la «lieutenance générale» des royaumes d'Aragon et de Valence, puis, à partir de 1454, de celle de la Catalogne ${ }^{140}$. Résidant habituellement à Saragosse, Jean dut se rendre plusieurs fois en Navarre pour livrer bataille à son fils Charles et à ses partisans. Ses armées surent chaque fois l'emporter : en 1451 à Aibar, puis en 1457 à Estella. Lorsque en 1458 Alphonse V mourut sans descendance légitime, Jean hérita de son frère la couronne d'Aragon. La rivalité de Charles de Viana avec son père prit un tour nouveau quand la Catalogne, où le prince, en sa qualité d'héritier présomptif, exerçait les prérogatives de lieutenant général, utilisa celui-ci dans ses efforts pour s'émanciper de l'union personnelle qui la liait à l'Aragon. La mort de Charles, en 1461, ne mit pas fin aux tensions entre Jean II et la principauté. Jusqu'en 1472, où capitula Barcelone, Jean II, qui comptait avec le renfort décisif de la noblesse aragonaise et valencienne, dut combattre par les armes la révolte catalane (qui, de son côté, reçut l'appui d'Henri IV de Castille) puis faire front, par les mêmes moyens, à une véritable révolution de la Generalitat. Voici quelques faits qui s'ajustent aux indications qui nous guident : proclamation pro-aragonaise, contraire à la Navarre et à la Catalogne, voire à la Castille; gouvernement et/ou domination militaire des Navarrais; fidélité au seigneur; une royauté, celle de Navarre, obtenue par le mariage.

Resteraient à élucider deux éléments de l'énigme identitaire. «Marquis par [son] père», Jean II ne le fut apparemment pas. Cependant, à considérer le genre énigmatique où nous sommes contraints de nous mouvoir, serait-il impensable que notre auteur ait songé rendre plus difficile son identification en rétablissant la seconde titulature, certes désuète, mais néanmoins traditionnelle, des comtes-marquis de Barcelone, rehaussant du même coup sa dignité, le titre de marquis (immédiatement inférieur à celui de duc) étant hiérarchiquement supérieur à celui de comte? Si tel était le cas, le Generatio aurait été écrit après que Jean, à la mort de son frère Alphonse V, aurait (héritant, en essence, de son père) reçu la Principauté, soit, après 1458. «Duc par [sa] mère». La mère de Jean,

139 Sur Jean II d'Aragon : Jaime VICÉNS VIVES, Juan II de Aragón, Barcelone, 1953; du même, Els Trastàmares (segle XV), Barcelone : Vicens-Vives, 1980 (2de éd.; 1ère éd. 1956), chapitre consacré à ce roi, p. 147-196; Ramón MENÉNDEZ PIDAL, dir., Historia de España , 15 (à charge de Luis SUáREZ FERNáNDEZ, Angel CANELLAS LóPEZ et Jaime VICÉNS VIVES), Madrid : Espasa Calpe, 1964.

$140 \mathrm{~J}$. Vicens Vives souligne également la fidélité de Jean à Alphonse dans son exercice de la viceroyauté sicilienne (El Trastàmares..., p. 148-149). 
femme de Ferdinand Ier le Juste (le Castillan Ferdinand d'Antequera), fut Éléonore Urraque de Castille, fille héritière de Sanche, frère d'Henri II de Trastamare. Les possessions castillanes d'Éléonore, qui était comtesse de Haro, Ledesma, Alburquerque et Medellín lui avaient valu le surnom de «La rica hembra» (la riche femme, version féminine singularisante de la dignité de riche homme). L'héritier de ces possessions et de ces titres fut d'abord l'infant Henri, Maître de Saint-Jacques, troisième fils de Ferdinand et Éléonore. Lorsque Henri mourut sans descendance à la suite des blessures reçues à la bataille d'Olmedo, en 1445, Jean de Navarre -Sanche et Pierre, ses deux autres frères cadets, étant morts respectivement en 1417 et en 1443- se tint pour héritier de droit des biens de sa mère. De droit, car à la suite de l'affrontement de Jean II de Castille et d'Alvare de Luna avec les rois d'Aragon et de Navarre, la royauté castillane, dès 1429, avait confisqué tous les biens castillans des «infants d'Aragon» ${ }^{141}$. Ces domaines ne leur furent jamais restitués, et sur la plupart Alvare de Luna fit un temps main basse. En 1454, lors des accords de paix d'Ágreda signés avec le jeune Henri IV de Castille, le roi de Navarre dut renoncer, contre une forte indemnité, à toutes ses seigneuries castillanes, y compris celles, également immenses, que Jean avait reçu de son père, dont le précieux duché de Peñafiel. En 1464, le roi de Castille donna le comté d'Alburquerque, promu pour l'occasion au rang de duché, à son favori Bertrand de la Cueva. Le duché resterait attaché à ce lignage pendant trois siècles. En dépit de la renonciation d'Ágreda et jusqu'à sa mort, Jean II, qu'un conflit constant opposa à Henri $\mathrm{IV}$, ne cessa de réclamer ses héritages castillans, notamment celui de sa mère. Après 1464, Jean II n'aurait donc pas menti tout à fait en se disant «duc par sa mère». Quatre décennies plus tard, dans ses Choses mémorables d'Espagne, Lucio Marineo Sículo, historiographe de Ferdinand le Catholique, fils de Jean II, ne vieillirait-il pas lui-même encore la titulature ducale en écrivant à propos du père de Jean, Ferdinand Ier : «Le dit

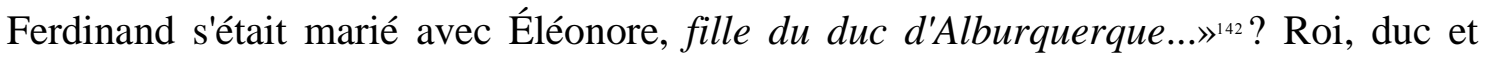
marquis : quelques petits arrangements avec la chronologie des titulatures auraient permis à Jean II d'Aragon de revêtir les trois plus hautes dignités laïques en même temps qu'il aurait rappelé toute l'étendue de ses droits : en Navarre, en Aragon, en Catalogne et en Castille.

\footnotetext{
141 On appelle «infants d'Aragon» les fils de Ferdinand Ier d'Antequera : Alphonse (Alphonse V d'Aragon), Jean (Jean Ier de Navarre et II d'Aragon), Henri (Maître de Saint-Jacques et comte d'Alburquerque), Sanche (Maître de Calatrava et d'Alcántara), Pierre (duc de Notho). Tous jouèrent un rôle politique important en Castille, terre de leurs parents, sous le règne de Jean II, au cours duquel une lutte d'influence les opposa constamment à Alvare de Luna.

142 Nieves BARANDA, «Una crónica desconocida de Juan II de Aragón (Valencia, 1541)», Dicenda, 7, 1988, p. 267-288. Cette chronique est en fait la traduction au castillan de la partie consacrée par Sículo au règne de Jean II dans son De rebus Hispaniae memorabilibus (Alcalá, 1530, livres 12 à 18). Dans le De genealogia, cependant, Sículo qualifie Éléonore de «comtesse d'Alburquerque» (Cronica d'Aragon, fol. $54 \mathrm{v}^{\circ}$.
} 
En évinçant de sa généalogie ses immédiats prédécesseur, Jean se serait offert le plaisir intellectuel de forger, grâce à une heureuse homonymie, une énigme préalable, à peine perceptible, qui contenait la réponse au complexe déploiement de l'énigme principale. Il aurait marqué en outre, se présentant comme l'héritier de Pierre IV le Cérémonieux, l'origine de ses droits à la couronne d'Aragon, et notamment à la Catalogne. Lorsque Martin Ier mourut sans descendant vivant, l'Aragon, la Catalogne et Valence eurent à lui désigner un successeur. Plusieurs candidats se présentèrent, tous munis d'excellents droits de succession, parmi lesquels les délégués des territoires de la couronne, réunis à Caspe en 1412, choisirent Ferdinand, fils d'Éléonore, elle-même fille de Pierre IV. C'est donc en tant que petit-fils de Pierre IV que, du point de vue des droits dynastiques, régna Ferdinand Ier tandis qu'étaient écartés ses principaux concurrents : Jacques, comte d'Urgell, arrière-petit-fils d'Alphonse IV; Alphonse, duc de Gandía, petit-fils de Jacques II; Louis, duc de Calabre, petit-fils de Jean Ier. Et c'est aussi en tant que descendant de Pierre -du point de vue d'un homme qui aurait le souci de rétablir une continuité dynastique des successions- que régnait Jean II. Peut-être n'était-il pas inutile d'en laisser quelque trace au moment où les Catalans, cherchant fiévreusement un nouveau roi, sollicitaient les descendants des prétendants de Caspe : en 1464, le connétable Pierre de Portugal, petit-fils du comte d'Urgell, puis en 1466, René d'Anjou, descendant de Jean Ier.

Voilà qui ferait du Generation regum Aragonum une oeuvre conçue par Jean II, dans sa bonne ville de Saragosse, entre 1464, date de la transformation du comté d'Alburquerque en duché, et 1479, année où mourut le roi d'Aragon. Son interprétation de l'histoire s'ajuste aux vues politiques, aux appuis et aux revendications qui furent ceux de Jean. Sa forme elle-même témoigne de l'intelligence d'un homme au règne long et compliqué à souhait, qui sut triompher, sur tous les terrains, d'à peu près tous ses ennemis, qui prépara l'union personnelle des royaumes d'Aragon et de Castille par le mariage de son fils Ferdinand avec Isabelle et reçut, dit-on, de Louis XI, expert s'il en fut en la matière, le surnom de «vieux goupil». L'écriture énigmatique était alors fort en vogue en Aragon ${ }^{143}$ et l'historiographie, on s'en sera rendu compte, y connaissait un vif essor. Jean II, lui-même très sensible aux utilités de l'histoire, avait nommé Vagad chroniqueur royal en 1466, un mois après la mort de l'«intrus» Pierre de Portugal ${ }^{144}$. Se jouant de la longue chronique composée par son fils abhorré Charles de Viana, aura-t-il laissé contre son flanc ce petit brûlot dont, par malice ou pour ne pas attacher sa

\footnotetext{
${ }^{143}$ Les XIVe et XVe siècles voient s'épanouir le goût de l'énigme en Espagne. Le langage énigmatique est consubstantiel à la dense littérature prophétique qui, précisément autour de Ferdinand Ier le Juste et de ses descendants, fleurit au XVe siècle en Aragon.

144 TATE, Ensayos..., p. 264-267.
} 
mémoire à ses audacieuses inexactitudes, il se sera gardé d'assumer trop clairement l'autorité?

Saragosse conserva néanmoins cette variante marginale sans doute chère aux élites d'Aragon et d'autres, dont les ouvrages connaîtraient un grand retentissement, prêtèrent quelque autorité au texte de qui lui avait lésiné la sienne. Vagad, le premier à s'en inspirer, écrivait dans un monastère cistercien des environs de Saragosse et c'est dans cette ville que, parmi d'autres chroniques d'Aragon ${ }^{145}$, il trouva sans doute notre Generatio. Mais ce fut Marineo Sículo qui, rencontrant notre texte lorsqu'il fouillait, à la demande des «députés d'Aragon», les «archives de Saragosse» ${ }^{146}$ ou, à l'instigation de Ferdinand le Catholique, père de notre supposé auteur, quelque mystérieuse «bibliothèque privée» de cette même cité ${ }^{147}$, l'accueillit avec le plus de sympathie et assura à son contenu la meilleure diffusion.

\footnotetext{
${ }^{145}$ Défendant la thèse «que [Garsias Jimenez] ne fut pas appelé roi de Navarre, mais que ce fut son fils Garsias Iñiguez, qui conquit Pampelune», Vagad évoque les chroniques d'Aragon «[qu'il vit] à Saragosse, que l'on apporta de là-bas et que bien d'autres ont vues», Coronica, fol. $8 v^{\circ}$.

${ }^{146}$ De genealogia, fol. $3 \mathrm{r}^{\circ}$.

147 Deux lettres de Sículo, datées de 1509, année où il achève son De genealogia en font foi. La première est adressée au roi lui-même, «Ferdinando Aragonum et utriusque Siciliae Regi». Elle s'ouvre ainsi : «Magnae prudentiae fuit consilium tuum sapientissime Rex : quo me Caesaraugustam uenire iussisti. Fuit enim meus huc aduentus et officio meo maxime necessarius et maiestatis tuae gloriae fructuosissimus. Siquidem historiam de rebus gestis Ioanis tui patris Aragonum et Siculorum regis magnanimi : multis rerum conquisitis argumentis et ordine digestis locis insertis : feliciter et ex uoto nostro consecimus». La seconde lettre est adressée à Ferrand de Ferrare, professeur à l'Université d'Alcalá de Henares. On peut y lire : «Caesaraugustam ueni quasi legatus a Ferdinando rege missus : cum ad alia conficienda negocia : tum uero praecipue : ut quedam de primis Aragoniae regibus monumenta : quae Hispano scripta sermone in quadam huius urbis priuata bibliotheca tanquam libri sibillini custodibus adhibitis asseruantur : in latinum uerterem». Epistolarum familiarium, Valladolid : Arnaldo Guillermo Brocario, 1514, respectivement livres 2 et 10 (les folios ne sont pas numérotés).
} 